\title{
Myelination- and immune mediated MR-based brain network correlates
}

\section{CURRENT STATUS: UNDER REVIEW}

JNI Journal of Neuroinflammation $\mathrm{E}$ BMC

Manuela Cerina

Universitatsklinikum Munster Klinik fur Neurologie mit Institut fur Translationale Neurologie

Muthuraman Muthuraman

Johannes Gutenberg Universitat Universitatsmedizin

mmuthura@uni-mainz.deCorresponding Author

ORCiD: https://orcid.org/0000-0001-6158-2663

Martin Gallus

Universitatsklinikum Munster Klinik fur Neurologie mit Institut fur Translationale Neurologie

Nabin Koirala

Johannes Gutenberg Universitat Universitatsmedizin

Andre Dik

Universitatsklinikum Munster Klinik fur Neurologie mit Institut fur Translationale Neurologie

Lydia Wachsmuth

Westfalische Wilhelms-Universitat Munster

Petra Hundehege

Universitatsklinikum Munster Klinik fur Neurologie mit Institut fur Translationale Neurologie

Patrick Schiffler

Universitatsklinikum Munster Klinik fur Neurologie mit Institut fur Translationale Neurologie

Jan-Gerd Tenberge

Universitatsklinikum Munster Klinik fur Neurologie mit Institut fur Translationale Neurologie

Vinzenz Fleischer

Johannes Gutenberg Universitat Universitatsmedizin

Gabriel Gonzalez-Escamilla

Johannes Gutenberg Universitat Universitatsmedizin 
Venu Narayanan

Universitatsklinikum Munster Klinik fur Neurologie mit Institut fur Translationale Neurologie

Julia Krämer

Universitatsklinikum Munster Klinik fur Neurologie mit Institut fur Translationale Neurologie

Cornelius Faber

Westfalische Wilhelms-Universitat Munster

Thomas Budde

Westfalische Wilhelms-Universitat Munster

Sergiu Groppa

Johannes Gutenberg Universitat Universitatsmedizin

Sven G Meuth

Universitatsklinikum Munster Klinik fur Neurologie mit Institut fur Translationale Neurologie

\section{DOI:}

$10.21203 / \mathrm{rs} .2 .21961 / \mathrm{v} 1$

\section{SUBJECT AREAS}

Neurobiology of Disease

\section{KEYWORDS}

Demyelination, Remyelination, Modularity, Network Dynamics, MRI 
Abstract

Background: Multiple sclerosis (MS) is an autoimmune disease of the central nervous system (CNS), characterized by inflammatory and neurodegenerative processes. Despite demyelination being a hallmark of the disease, how it relates to neurodegeneration has still not been completely unraveled, and research is still ongoing into how these processes can be tracked non-invasively. Magnetic resonance imaging (MRI) derived brain network characteristics, which closely mirror disease processes and relate to functional impairment, recently became important variables for characterizing immune-mediated neurodegeneration, however their histopathological basis remains unclear. Methods: In order to determine the MRI-derived correlates of myelin dynamics and to test if brain network characteristics derived from diffusion tensor imaging reflect microstructural tissue reorganization, we took advantage of the cuprizone model of general demyelination in mice and performed longitudinal histological and imaging analyses with behavioral tests. By introducing cuprizone into the diet, we induced targeted and consistent demyelination of oligodendrocytes, over a period of 5 weeks. Subsequent myelin synthesis was enabled by reintroduction of normal food. Results: Using specific immune-histological markers, we demonstrated that two weeks of cuprizone diet induced a $52 \%$ reduction of myelin content in the corpus callosum (CC) and a $35 \%$ reduction in the neocortex. An extended cuprizone diet increased myelin loss in the CC, while remyelination commenced in the neocortex. These histologically determined dynamics were reflected by MRI measurements from diffusion tensor imaging. Demyelination was associated with decreased fractional anisotropy (FA) values and increased modularity and clustering at the network level. MRI-derived modularization of the brain network and FA reduction in key anatomical regions, including the hippocampus, thalamus and analyzed cortical areas, were closely related to impaired memory function and anxiety-like behavior. Conclusion: Network specific remyelination, shown by histology and MRI metrics, determined amelioration of functional performance and neuropsychiatric symptoms. Taken together, we illustrate the histological basis for the MRI-driven network responses to demyelination, where increased modularity leads to evolving damage and abnormal behavior in MS. Quantitative information about in vivo myelination processes is mirrored by diffusion based imaging 
of microstructural integrity and network characteristics.

Introduction

Myelinated fibers in the white matter (WM) assure the effective communication between anatomical regions and essential influence brain function. Alteration in myelin composition in WM pathways or in grey matter (GM) regions can lead to severe impairment of brain functioning (Huntenburg et al., 2017). WM and GM integrity relates to physiological functioning and mirrors pathological processes (Groppa et al., 2014; Fleischer et al., 2019b; Fleischer et al., 2019a). Addressing structural integrity with non-invasive magnetic resonance imaging (MRI) provides quantitative and correlative measures of tissue integrity. It robustly detects neuroinflammation and neurodegeneration as seen in multiple sclerosis (MS; (Gamboa et al., 2014; Muthuraman et al., 2016; Filippi et al., 2019). However, it is not clear how microstructural integrity drives the entire network behavior and how it is related to histopathology and behavior. Diffusor tensor imaging (DTI) based on anisotropic water diffusion is a powerful method for non-invasive, highly sensitive estimation of WM structures in the brain, reflecting macroscopic axonal and myelin organization of fiber bundles (Huntenburg et al., 2017; Madden et al., 2012; Salat et al., 2005; Soares et al., 2013; Westlye et al., 2010). Recent animal studies have shown that the myelin content of WM accounts to a larger extent for the variance of the DTI derived fractional anisotropy (FA) scalar index (Chang et al., 2017), providing evidence that diffusion anisotropy measures in these regions are highly sensitive to myelination (Chang et al., 2017; Inano et al., 2011; Song et al., 2005, 2002). Reconstructing network properties of the entire brain enables a robust characterization of alterations that are caused by pathological processes. In support of this view, analysis of network properties as derived from structural similarity measures in vivo showed network alterations (for WM and GM, (Deppe et al., 2016; Mangeat et al., 2018)) and associations between FA and level of demyelination, both for MS patients (Granberg et al., 2017) and animal models of neuroinflammation (Hübner et al., 2017). In a similar manner, alterations of thalamocortical pathways were described for other diseases and suggest a more complex scenario than just the measurable morphological alterations (Groppa et al., 2012; Harsan et al., 2013; Liang et al., 2013; Moeller et al., 2013). 
Pre-clinical studies have reported altered brain tissue properties in animal models of de- and remyelination (Crawford et al., 2009; Thiessen et al., 2013; Guglielmetti et al., 2016; Jelescu et al., 2016) and in models of experimental autoimmune encephalitis (Ellwardt et al., 2018; Potter et al., 2016). Alterations followed specific regional patterns and occurred within specific temporal scales that were associated with periods of neuroinflammation (Cerina et al., 2018; Chanaday et al., 2015; Ellwardt et al., 2018; Potter et al., 2016). However, it remains unclear to which extent network characteristics mirror the level of de- and remyelination or inflammation. Moreover, it is not clear how network dynamics determine functional impairment and whether remyelination promotes complete recovery. We previously demonstrated that impaired cognitive function associated with demyelination were only restored by promoting remyelination when solely WM was affected, while de- and remyelination in cortical GM was still associated with functional alterations (Cerina et al., 2017; Narayanan et al., 2018). Beside a clear spatial pattern, there seem to be mechanisms triggered by myelin loss that prevent full functional recovery.

To understand these dynamics - namely, when does myelin loss affect brain circuits at the network level and how it is related to behavioral performance, we make use of the cuprizone model of de- and remyelination. This is an animal model robustly used to study consequences of myelin loss under pathological conditions (Crawford et al., 2009b; Hamada and Kole, 2015). Loss of myelin alters structure and architecture of neural networks, and hence may have a major impact on brain functioning (Goulas et al., 2017). The mechanisms underlying such alterations have been partially identified as altered distribution of ion channels following myelin loss (Crawford et al., 2009; Hamada and Kole, 2015) and alteration of tissue excitability (Cerina et al., 2018; Dutta et al., 2013, 2011), with subsequent cognitive deficits (Cerina et al., 2018, 2017; Gregg et al., 2009; Serra-de-Oliveira et al., 2015) but not obvious locomotor impairment (Serra-de-Oliveira et al., 2015).

Myelin loss persists as long as cuprizone is added to the diet. When cuprizone is omitted, spontaneous remyelination occurs and control-like levels of myelin are observed after only three weeks (Cerina et al., 2018, 2017; Matsushima and Morell, 2001). To closely track these dynamics on brain network characteristics and microstructural tissue properties, we investigated de- and remyelination processes 
in the cuprizone model at different time points by acquiring structural MRI data (including DTI), performing ex-vivo histopathology, and applying behavioral testing. Our data show that myelin loss and regain can be identified with immunohistological approaches, and the outcome matches results from in vivo structural MRI. While myelin levels follow the diet progression and cuprizone withdrawal afterwards, alterations of fractional anisotropy and network topology are associated with altered cognitive abilities and activated microglia which are still observed during remyelination and suggest permanent damage at the neuronal level (Bitsch, 2000; Boretius et al., 2012; Gudi et al., 2014).

\section{Material And Methods}

\section{Animals and experimental outline}

The experiments were performed on C57BL6J mice (females, 9 weeks old at the beginning of

treatment, Envigo, Rossdorf, Germany). Experiments were conducted in accordance with guidelines of local German authorities (LANUV ID: 84-02.04.2015.A585). All efforts were made to minimize stress for the animals in accordance with the ARRIVE guidelines (Kilkenny et al., 2010). Food and water were available ad libitum.

Cuprizone [bis(cyclohexylidenehydrazide)] was mixed with rodent pellet chow $(0.2 \%)$. This compound is toxic for mature oligodendrocytes because it interferes with their internal mitochondrial metabolism and induces full demyelination after 6 weeks of diet. Omitting this compound from the diet allows spontaneous remyelination (Matsushima and Morell, 2001). Mice were divided into 6 experimental groups: (i) 2, (ii) 4 and (iii) 6 weeks of cuprizone diet (model of demyelination, cupri 2, 4 and 6 weeks in the text), and 6 weeks of cuprizone diet followed by (iv) 1, (v) 3 and (vi) 6 weeks of normal food (model of remyelination, remy 1, 3 and 6 weeks in the text). A control group was matched for gender and age and received normal food for the whole duration of the study (see Fig. 1).

The same cohort of mice was longitudinally investigated by means of MRI and DTI. A new cohort of mice was used for each time point for behavioral tests (OF, EPM and NOR) and some of the mice, as specified below, were used for ex vivo histological evaluation. A new cohort of mice was used to perform Pavlovian conditioning paradigms only in control conditions, after 6 weeks of cuprizone diet, at 1 week and 6 weeks of remyelination as shown in the experimental outline in Fig. 1. Imunohistochemistry 
In order to evaluate the efficacy of the cuprizone diet, 3 to 10 animals which participated in behavioral tests were used for histopathological evaluation. Briefly, mice were deeply anesthetized using ketamine/xylazine and transcardially perfused using phosphate-buffered saline (PBS), as described before (Cerina et al., 2017). Afterwards, brains were quickly removed, embedded in cryoprotective compound (TissuTeK, Science Service GmbH, Munich, Germany) and frozen using liquid nitrogen. Coronal cryo-sections (10 $\mu$ m thickness) were cut using a cryotome (Leica), positioned on glass slides (two per slide) and conserved at $-20^{\circ} \mathrm{C}$. Slices were fixed in a solution containing $4 \%$ paraformaldehyde (PFA) for 10 minutes and then washed with PBS. In order to avoid false-positive results, slices were incubated overnight at $4{ }^{\circ} \mathrm{C}$ with a blocking solution containing PBS, $0.03 \%$ Triton X-100, 10\% goat serum and 10\% bovine serum albumin (BSA). After blocking, slices were incubated with following primary antibodies: proteolipid protein (PLP, product number \#9311, mouse antimouse, Abcam, Cambridge, UK, 1:250) a specific marker for myelin; glial fibrillary acidic protein (GFAP, product number \#7260, rabbit anti-mouse, Abcam, 1:1000) a specific marker for astrocytes; ionized calcium-binding adapter molecule 1 (Iba1, product number \#019-19741, rabbit anti-mouse, Wako Chemicals Inc., Richmond, VA, USA, 1:250) a specific marker for microglia.. Antibodies were diluted in a cold solution containing $10 \%$ goat serum, $10 \%$ BSA and PBS. Overnight incubation followed. Slides were then incubated for 1 hour with the fluorophore-conjugated secondary antibody Cyanine Cy ${ }^{\mathrm{TM}} 3$ for Iba-1 (goat anti-rabbit IgG, \#111-165-144, A=550, E=570 nm, Jackson ImmunoResearch Inc., 1:300). Finally, the mounting medium Fluoromount-G ${ }^{\mathrm{TM}}$ containing DAPI (\#004959, Invitrogen by Thermo Fisher Scientific, San Diego, CA, USA) was applied as marker for cell nuclei. To visualize PLP and GFAP, a 3,3-Diaminobenzidine (DAB)-based protocol was used according to the manufacturer's instructions. Briefly, the secondary antibody (Biotin conjugated goat anti-mouse IgG, DAB-87582, dianova GmbH, Hamburg, Germany) was applied at room temperature and incubated for 1 hour. Then the avidin-biotin complex interaction method was used to specify the signal. For this purpose, the Vectastain A+B set (PK-6100, Vector Laboratories, Burlingame, USA, 1:100) and Tris-buffered saline (TBS) were applied for 35 minutes (Fahimi and Herzog, 1973). Immunohistochemistry analysis 
Images were acquired using a Zeiss Examiner microscope. Images of slices containing the corpus callosum (CC), the neocortex $(\mathrm{Cx})$ and the thalamus (Th) were collected from both hemispheres. A maximum of 11 slices per mouse were analyzed and considered as technical replicates for analysis of CC and Cx while more slices were used for analysis of the thalamus. All image analyses were performed in a blinded manner using ImageJ (Schneider et al., 2012). For PLP staining, images collected at a magnification of 5- and 10-fold were used for analysis. Myelin intensity, corresponding to intensity of DAB staining, was used as read-out and compared to control for all other experimental groups. For GFAP staining, images were acquired using 20- and 40-fold objectives and analyzed by counting the number of DAB positive cells per $\mathrm{mm}^{2}$. For lbal, images were acquired using a 20-fold objective and analyzed by counting the number of fluorescence positive cells per $\mathrm{mm}^{2}$.

\section{Behavioral tests}

Mice underwent a series of tests to evaluate locomotor activity, anxiety-levels and cognitive performance.

Locomotor activity. The open field (OF) test was applied in order to evaluate locomotor activity and basal exploratory behavior. Animals $(\mathrm{n}=10)$ were tested in the OF arena $(35 \times 40 \times 40 \mathrm{~cm})$. The distance covered and time spent in the periphery were taken as a read-out (Noldus Ethovision, The Netherlands).

Characterization of anxiety-like behavior. Animals ( $n=10$ for the control group and $n=5$ for the other groups) were tested in the Elevated Plus Maze (EPM, Ethovision, Noldus IT bv, Wageningen, The Netherlands) to assess anxiety-like behavior. The EPM system is elevated from the floor $(50 \mathrm{~cm})$ with two closed and two open arms which the animal is allowed to explore for 5 minutes. Each group was tested once and time spent in closed and open arms was taken as read-out.

Auditory Pavlovian conditioning. A modified auditory fear conditioning paradigm was used, as described previously (Cerina et al., 2017; Daldrup et al., 2015; Narayanan et al., 2011). Mice $(n=5)$ were familiarized with the fear conditioning apparatus (TSE System GmbH, Bad Homburg, Germany) twice during one day (with a 6-hour interval) while being exposed to six neutral tones (unconditioned stimulus $\mathrm{CS}^{-}, 2.5-\mathrm{kHz}$ tone, $85 \mathrm{~dB}, 10-\mathrm{s}$ duration; referred to as non-relevant stimulus in the text). On 
the next day, animals were exposed to the conditioned stimulus (three trials; $\mathrm{CS}^{+}, 10-\mathrm{kHz}^{\mathrm{H}}$ tone, 85 dB, 9-s duration) randomly coupled with a mild foot shock (0.4 mA, 1-s duration, onset with CS termination). Then, 24 hours after the last tone presentation, animals were again randomly presented with two tones, and freezing was taken as behavioral read-out. Freezing is the duration of immobility of the animal (except for respiratory movements) in response to presentation of the conditioned stimulus (10 kHz), as described previously (Cerina et al., 2017; Daldrup et al., 2015; Narayanan et al., 2011).

Short- and long-term memory skills. Novel Object Recognition (NOR) was performed to evaluate cognitive and memory skills of the animals ( $n=10$; all time points; Ethovision, Noldus IT bv, Wageningen, The Netherlands). We used the same arena as for the OF test, since the animals were already familiar with it. The NOR test consists of a habituation phase during which animals are allowed to explore two identical objects for $10 \mathrm{~min}$, followed by three retrieval phases performed at different time intervals after habituation in order to evaluate short non-hippocampal-related (15 min), short hippocampal-related (4 h) and long-term memory (24 h) skills (Hammond et al., 2004). For each retrieval session, one of the old objects was substituted for a novel one (chess pieces were used for all tests). Time spent exploring novel and old objects was used to calculate a NOR index (Kaiser et al., 2014) as follows: (time novel)/(time novel + time old). An index $>0.5$ indicates that animals spent more time exploring the novel object than the old one, suggesting proper memory skills; an index = 0.5 indicates that animals spent an equal amount of time exploring the novel and old object, suggesting their inability to distinguish between the novel and the old (Antunes and Biala, 2012). A new cohort of mice was used for each of the seven time points described above in order to avoid learning effects and they underwent OF, EPM and NOR testing. Additional new cohorts of mice were used for Pavlovian Conditioning Paradigm which was only performed in control mice, after 6 weeks of cuprizone diet, 1 week and 3 weeks after reintroduction on normal food.

\section{MRI and DTI}

MRI was performed using a 9.4-Tesla small animal MR scanner with a mouse brain surface coil (Bio-

Spec 94/20; Bruker BioSpin MRI GmbH, Ettlingen, Germany). Mice ( $\mathrm{n}$ for each group is given in the 
results) were anesthetized with isoflurane. We obtained T1- and T2-weighted (T2w) rapid acquisition with relaxation enhancement anatomical images. Diffusion tensor data were acquired with an eightsegment echo planar imaging (EPI)/diffusion tensor imaging (DTI) protocol (repetition time/echo time, $5000 / 30 \mathrm{~ms}$, slice thickness $0.3 \mathrm{~mm}$ (20 slices), matrix size $(128 \times 128)$ resulting in an in plane resolution of 125 ) with $b=0,1000 \mathrm{~s} / \mathrm{mm}^{2}$ (30 diffusion directions, five $\mathrm{B}_{0}$ images, diffusion gradient duration of $5 \mathrm{~ms}$, and diffusion gradient separation of $11 \mathrm{~ms}$ ).

In accordance with the FSL (www.fmrib.ox.ac.uk/fsl) DTI pipeline, and after pre-processing for artefact correction (eddy currents and head movements), individual masks were generated for each mouse brain using the Brain Extraction Toolkit (BET) to isolate the brain from the skull. These masks were subsequently edited manually to correct for errors remaining from the masking process. A studyspecific high-resolution mouse template was generated by nonlinearly registering each mouse brain to a single reference image. Further, output of non-linear registration was validated by checking for correct alignment of the surface of the brain and internal alignment of anterior commissure, corpus callosum, and cerebellum. An averaged image of registered brains was constructed and used as reference image for subsequent analyses, and transformation matrices were generated between the reference image and individual mouse brain data sets using FNIRT (FSL, www.fmrib.ox.ac.uk/fsl) (Gutman et al., 2013). Fractional anisotropy (FA) values were obtained using FSL (http://www.fmrib.ox.ac.uk/fsl/). The detailed protocol is explained elsewhere (Smith et al., 2004). In addition, distribution of crossing fibers was estimated using BEDPOSTX (implemented in FSL), and probability of major (f1) and secondary (f2) fiber directions was calculated (Behrens et al., 2007). Tractography was then computed for each voxel within the seed mask (using $n=5000$ streamline fibers/voxel and curvature threshold of 0.2 ) and back-transformed into high-resolution mousestandard space (Jenkinson et al., 2012). Allen mouse brain atlas (AMBA) with 82 identified brain regions was used (Hübner et al., 2017; Lein et al., 2007). Thus obtained fiber tracts were mapped to the FA skeleton for each animal to obtain FA values in the tracts between ROI's (Pavuluri et al., 2009). Hence, a final $82 \times 82$ connectivity matrix was estimated based on the correlation of mean FA values of 
fiber tracts between those regions for each subject.

The obtained connectivity matrices were then investigated using the graph theoretical network framework to obtain various local and modular measures which would describe the topological reorganization of structural networks associated to the histological markers and behavior changes. The networks were then obtained at 20 different network densities and the measures were extracted at each density. In graph theory analyses, the density represents cost of the network computed by fraction of present connections to all possible connections (Hosseini et al. 2012). Hence, the network measures derived at each density for each time point would specify the alterations in network behavior between these time points at different levels of network fragmentation (from full, partial to discontinuous connectivity). This method of thresholding ensures that all the regions (nodes) of the network are connected while discarding spurious connections (edges) (Achard and Bullmore, 2007). The local network measure was observed by computing "clustering coefficient" (Watts and Strogatz, 1998), and the modular reorganization was observed using "modularity" (Girvan and Newman, 2002; Newman, 2006). All these measures were computed using BCT toolbox (Rubinov and Sporns, 2010). It has been shown that addressing both of these variables gives a robust conceptual characterization of the network characteristics at different systemic ranges (Fleischer et al., 2017).

\section{Statistics}

All data are presented as means \pm standard error mean (SEM), or medians with ranges. Analyses of variance (ANOVA) and covariance (ANCOVA) were performed using one way- or factorial models (ANOVAs) followed by Tukey's or Bonferroni's post-hoc tests (SPSS, IBM). Statistical analysis of histological results was performed using nested ANOVAs performed with GraphPad (Prism 8) in order to take into consideration technical replicates and biological ones and test for random effects. The other statistical analyses were performed using IBM SPSS Statistics, Version 22.0 (SPSS, Chicago, Illinois, USA) and GraphPad (Prism 5). Graphs were produced using Prism 5, and figures were created with Coreldraw x8.

Results Time-dependent white matter de- and remyelination in the cuprizone model Two weeks after the mice started on the cuprizone diet, the myelin intensity signal, which was 
evaluated in the corpus callosum (CC) using the specific marker PLP, was lower compared to control (198.2 \pm 4.01 vs. $231.1 \pm 4$ respectively, nested ANOVA, $F_{(6,26)}=19.55, p<0.0001$; Tukey's posthoc test: cupri 2 weeks vs. control, $p=0.05$; Fig. 2a and Supplementary Fig.1a). The myelin intensity signal decreased constantly with continuation of the diet, reaching a minimum 6 weeks after starting the diet, evidencing large demyelinated white matter regions in the lateral part of the CC (127.9 \pm 11.1, vs. control, $p<0.0001 ;$ Fig. $2 a$, middle column). In line with previous reports (Matsushima and Morell, 2006; Skripuletz et al., 2011), omitting cuprizone from the diet allowed remyelination: the myelin intensity constantly and significantly increased in comparison to the time point of maximal demyelination (cuprizone 6 weeks). Myelination values reached control-like levels 6 weeks after cuprizone withdrawal ( $221 \pm 4.75 ;$ Fig. 1 a, $1^{\text {st }}$ and $3^{\text {rd }}$ column and bar graph).

Demyelination was accompanied by activation of the innate immune system, namely by astrocytosis and microgliosis. In detail, the number of astrocytes observed in the CC was significantly higher in the presence of cuprizone already 2 weeks after starting the diet compared to control conditions (526.3 \pm 21.6 cells $/ \mathrm{mm}^{2}$ and $391.3 \pm 9.6$ cells $/ \mathrm{mm}^{2}$, respectively; nested ANOVA, $F_{(6,63)}=48.51, p<0.0001$; Tukey's post-hoc test, $\mathrm{p}<0.0001 ;$ Fig. 2b). This number further increased 6 weeks after starting the $\operatorname{diet}(738.2 \pm 24.55 ; p<0.0001$ vs. control, Fig. 2b). Interestingly, the number of astrocytes decreased during early and late phases of remyelination, almost reaching control-like values (remy 1 week: $428.7 \pm 13.9$ cells $/ \mathrm{mm}^{2}$; remy 3 weeks: $421.2 \pm 12.21$ cells $/ \mathrm{mm}^{2}$, remy 6 weeks: $421.6 \pm 7.78$ cells/mm²; Fig. 2b).

Activated microglial cells can be distinguished from silent resident microglia due to their morphology and size (Cerina et al., 2017). Compared to the control group, we observed a general effect of the cuprizone diet on the number of activated microglial cells was already increased 2 weeks after starting the cuprizone diet althought not significantly $\left(20.25 \pm 3.9\right.$ cells $/ \mathrm{mm}^{2}$ and $103.5 \pm 11.9$ cells $/ \mathrm{mm}^{2}$, respectively; nested ANOVA, $\mathrm{F}_{(6,23)}=5.36, \mathrm{p}=0.0014$; Tukey's post-hoc test: control vs. cupri 2 weeks, $p=0.27$; Fig. 2c and Supplementary Fig. 1b). This number further increased to reach a 
peak 6 weeks after starting the diet $\left(192.6 \pm 22.34\right.$ cells $/ \mathrm{mm}^{2}$, vs. control, $\left.p=0.0009\right)$. Their levels remained significantly higher than control during all considered remyelination time points (control vs. remy 1 week and remy 3 weeks, $p=0.013$ and $p=0.021$, respectively, Fig. $2 c$, bar graph and Supplementary Fig. 1c). Yet, the number of activated microglial cells decreased in comparison to the time point of full demyelination. Notably, the overall number of microglial cells did not change between experimental groups indicating that already present resident cells changed to an activated state upon diet (Supplementary Fig. 2). This is in line with literature since the cuprizone model is not characterized by blood brain barrier breakdown and therefore no peripheral cell infiltration is expected (Gudi et al., 2014; Matsushima and Morell, 2006). However, activation of the innate immune system is described to be a critical phase in the cuprizone model as activated microglial cells can phagocytose debris of myelin and dead oligodendrocytes therefore allowing oligodendrocyte progenitors to reach demyelinated areas and start the synthesis of new myelin (Döring et al., 2015; Hall, 1972).

Analyzing T2-weighted images evidenced a morphologically similar extent of demyelination in the CC, visible in the lateral part of this structure thereby validating our ex vivo experimental findings. Since myelin, given its lipid composition, appears hypointense in T2-weighted MR images, white matter regions appear darker than grey matter ones. Analysis of myelination intensity was carried out by calculating the ratio between the hyperintense signal from the cortex and the myelin hypointense signal of the CC. Control conditions were characterized by a high ratio, namely, high differences between the two signals ( $54.9 \pm 3.6, n=5$; Fig. $1 d$, first column and bar graph). Corroborating the histological results, the ratio calculated 2 weeks after starting the diet was already significantly lower than control $\left(23.58 \pm 1.8\right.$, One-way ANOVA, $F_{(6,57)}=29,31, p<0.0001$; Tukey's post-hoc test: $p$ $<0.0001$ vs. control, $n=12 ;$ Fig. $1 d$ ). The ratio did not significantly decrease any further 4 and 6 weeks after starting the diet $(17.65 \pm 1.8$ and $20.87 \pm 2.43$, respectively, $p<0.0001$ vs. control, $n=$ 12; Fig. 1d). Allowing remyelination by re-introducing normal food into the diet induced an increase of the ratio at 1 week $(n=5)$ and 3 weeks of remyelination $(n=10)$, although values were still 
significantly different compared to control ( $p=0.013$ and $p<0.0001$, respectively vs. control). Only at 6 weeks of remyelination values reached control-like levels $(44.3 \pm 2.03, n=10 ; p=0.085)$. Time-dependent grey matter de- and remyelination in the cuprizone model Next, in order to assess potential differences between white and grey matter regions upon cuprizone administration and withdrawal, we performed a structural analysis, similar to the one described above, but in the neocortex parenchyma (Cx). Already 2 weeks after starting the diet, myelin intensity evaluated in the Cx showed a tendency to be lower in comparison to control (117.5 \pm 34.6 and 223.2 \pm 24.41 , respectively; nested ANOVA, $F_{(6,20)}=1.79, p=0.15$; Fig. 3a and Fig. 3e and Supplementary Fig. 3a). However, contrary to the CC, we did not observe large demyelinated areas, compared to control, at a similar time point (cupri 6 weeks: $255.9 \pm 20.07$, Fig. 3a, middle column). This finding could be attributed to the low myelin content known to characterize some of the grey matter regions in comparison to white matter ones (Klaver et al., 2013). Similarly, no changes, compared to control, were observed during remyelination (remy 6 weeks: $198.8 \pm 22.3$, left column; Fig. 3a). Astrocytosis and microgliosis were also observed in the neocortex (Fig.3b). The number of astrocytes (control: $57.94 \pm 10.83$ cells $/ \mathrm{mm}^{2}$ ), was found to be significantly higher than control already 2 weeks after starting the diet $\left(165.9 \pm 15.1\right.$ cells $/ \mathrm{mm}^{2}$; nested ANOVA, $\mathrm{F}_{(6,20)}=4.86, \mathrm{p}=0.0036$; Tukey's post-hoc test: control vs. cupri 2 weeks: $p=0.006$; Fig. 3b and Supplementary Fig. 3b) and it remained relatively elevated at all investigated time points.

We observed a tendency to an higher number of activated microglial cells in comparison to control $\left(45.9 \pm 8.4\right.$ cells $/ \mathrm{mm}^{2}$ ) at maximal demyelination (cupri 6 weeks: $111.4 \pm 22.5$ cells $/ \mathrm{mm}^{2}$ ) but this failed to reach significance threshold (nested ANOVA, $F_{(6,21)}=1.62, p=0.18$; Fig. $3 c$ and Supplementary Fig. 3c) probably because the number of cells was very variable at intermediate time points during demyelination. In contrast to the CC, promoting remyelination in this grey matter region fully restored control-like values $\left(55.5 \pm 11.3 \mathrm{cells} / \mathrm{mm}^{2}\right)$. The same holds true for other grey matter regions like the somatosensory thalamus (Supplementary Fig.4 and 5). Behavioral correlates of general de- and remyelination 
Next, we performed behavioral experiments to investigate associations between the histological alterations and region-related functions such as cognition, anxiety-like behavior, and locomotor activity (Fig. 4). Therefore, in order to facilitate temporal presentation of the following behavioral data, a synopsis of histological evaluation in cortical white (Fig. 4a, left panel) and grey matter (Fig. $4 a$, right panel) is presented.

Animals tested in the OF two- $(165.6 \pm 12.35 \mathrm{~cm}$, Fig. 4b) and six weeks $(165.1 \pm 14.97 \mathrm{~cm})$ after starting the cuprizone diet travelled a significantly longer distance in comparison to control (104.7 \pm $9.24 \mathrm{~cm}$, One-way ANOVA, $\mathrm{F}_{(6.62)}=4.9, \mathrm{p}=0.0004$; Tukey's post-hoc test: cupri 2 weeks and cupri 6 weeks vs. control, $\mathrm{p}<0.01$, Fig. 4b). This indicates locomotor hyperactivity of the mice, a behavior which was described previously (Tezuka et al., 2013) and seemed to be characteristic of demyelinated mice as animals from all remyelination time points travelled a similar distance as control animals ( $p=0.016$ vs. remy 6 weeks; Fig. 4b). To assess the level of anxiety-like behavior due to the new environment, we measured the amount of time animals spent in proximity of the walls and corners, both considered as shelter places. The group that received cuprizone for 4 weeks spent significantly more time in proximity to the walls (128.8 $\pm 8.64 \mathrm{~s}$, Fig. 4b) compared with control animals (88.6 $\pm 15 \mathrm{~s})$ and the other groups. This indicates anxiety-like behavior rather than locomotor impairment as there were no obvious differences in distances travelled (One way ANOVA, $F_{(6,62)}=$ 5.82, $p<0.0001$; Tukey's post-hoc test: cupri 4 weeks vs control: $p=0.048$, vs. cupri 2 weeks: $p=$ 0.002 , vs. cupri 6 weeks: $p<0.0001$, vs. remy 1 week: $p=0.012$, and vs. remy 3 and 6 weeks: $p<$ 0.001, Fig. 4b).

To further interpret these findings, we performed the EPM test which is based on the normal exploration attitude of mice. Non-anxious, control mice spent an equal amount of time in the two arms (open: $77.6 \pm 15.9$, closed:103.7 \pm 10.6 , Fig. 4c), while the animals on a 2-week cuprizone diet spent most time in closed arms (159.4 $\pm 48.3 \mathrm{~s}$ vs. open arms, $38.5 \pm 17.7 \mathrm{~s}$, Two-way ANOVA, effect of the anxiety: $F_{(1,66)}=31.7, p<0.001$; Tukey's post-hoc test: cupri 2 weeks open vs. closed arms: $p$ $<0.01$, Fig. 4c). Similar anxiety-like behavior was observed during the first 3 weeks of remyelination 
(closed arms: $141.37 \pm 9.7$ s), and still persisted after 6 weeks of remyelination (closed arms: $141.8 \pm$ 3.9 s). This marked anxiety-like behavior does not depend on pre-existing locomotor deficits and coincides with microglia activation observed both in grey and white matter during the remyelination period.

Next, we assessed the cognitive and learning abilities of the mice. Our previously published experiments (Cerina et al., 2018, 2017) demonstrate that demyelination heavily impairs the ability to retrieve information from different brain regions. Here, we chose the auditory Pavlovian conditioning paradigm, which, in accordance with our previous findings, revealed that cuprizone-treated mice fail in associating a specific tone frequency with aversive stimuli (Fig. 4d). Moreover, animals tested during early and late stages of remyelination (freezing at $2.5 \mathrm{kHz}$ : $50 \pm 2.9 \%$ and freezing at $10 \mathrm{kHz}$ : $62.3 \pm 4.5 \%$; Two way ANOVA, effect of the diet, $F_{(1,32)}=28.3, p<0.0001$, Tukey's post-hoc test 2.5 kHz vs. $10 \mathrm{kHz}$, not significant, Fig. 4d) showed the same outcome as control mice (freezing at 2.5 kHz: $9.8 \pm 1.03 \%$ and freezing at $10 \mathrm{kHz}: 59.7 \pm 3.4 \%$; Tukey's post-hoc test $2.5 \mathrm{kHz}$ vs. $10 \mathrm{kHz}, \mathrm{p}<$ 0.001; Fig. 4d), confirming that myelin loss triggers mechanisms that alter neuronal circuits associated with tone frequency discrimination as well as fear learning and memory. The impairment persisted after 3 weeks of remyelination (Fig. 4d). On this basis, we applied another well-established method to investigate short- and long-term memory abilities: the Novel Object Recognition (NOR) test. Test was performed $15 \mathrm{~min}$ and 4 hours after adaptation to test short term memory and $24 \mathrm{~h}$ to assess long term memory. Control animals recognized the novel object at all of the chosen time intervals, while impaired memory skills seemed to arise with diet onset and constantly progressed to an inverted performance 6 weeks after starting the diet (cupri 6 weeks: $24 \mathrm{~h}: 0.33 \pm 0.03$, Two-way ANOVA, effect of the diet: $F_{(6,165)}=7.87, p<0.0001$; Fig. 4e). After reintroduction of normal food, the performance of mice ameliorated, reaching control-like values for short-term memory intervals already in the first week of remyelination, and for long-term memory intervals in the third week of remyelination. Taken together, our data suggest that improvement of memory abilities goes hand in hand with spontaneous remyelination.

DTI analysis depicts altered FA values while the network analysis shows a 


\section{regional discrepancy between cortex and thalamus}

The structural MRI data were further evaluated to analyze the FA and to build structural similarity maps for the entire brain. T2-weighted MR images and DTI related parameters such as FA were extracted to measure structural similarity of the ROIs from the anatomical atlas. Cortex and hippocampus showed reduced FA values indicating a demyelination over time effect 6 weeks after starting the diet compared to control (one-way ANOVA, thalamus $-F_{(6,83)}=5.81, p<0.001$;

hippocampus $-F_{(6,83)}=4.74, p<0.001$; cortex $-F_{(6,83)}=6.23, p<0.001$; corpus callosum $-F_{(6,83)}=$ 4.98, $p<0.001 ;$ Fig. 5b). The post-hoc comparisons between the other time intervals for all four regions were significant ( $p<0.001$ ) except for thalamus at cuprizone 2 weeks, and for the other three regions at the remyelination 6 weeks as shown in Fig. 5b with dashed line. In cortex and hippocampus FA recovered with reintroduction of normal food, following a similar time course as observed for myelin markers (Fig. 5b). However, analysis of thalamic FA indicated that this region only shows very low FA values during early remyelination, indicating a network abnormality in comparison to neocortical integrity. Adressing the network properties we depict increased global clustering (Fig. 5c, left) and increased modularity over time (Fig. 5c, right) shows higher short range connections, while compared to controls (for one-way ANOVA: clustering, $F_{(6,139)}=27.2, p<0.001$; modularity, $F_{(6,139)}=$ 22.3, $\mathrm{p}<0.001)$. The post-hoc comparisons between the control and the other time intervals for both parameters were significant $(p<0.001)$ except for the clustering coefficient between remyelination 3 and 6 weeks $(p<0.01)$, and the modularity between control and cuprizone 2 weeks $(p<0.01)$ and between remyelination 3 and 6 weeks $(p<0.01)$.

So far, we investigated histopathological differences between white and grey matter regions in the cuprizone model of general de- and remyelination. Moreover, we linked these differences to specific behaviors and changes in brain connectivity observed with the help of in vivo approaches. As final step, we performed correlation analyses to further characterize the role of white and grey matter myelination in a disease model. A positive correlation was observed between the number of GFAP positive cells in the cortex and the FA values (Fig. 6a and Table 1), thus supporting the relation between astrocyte count and MRI driven microstructural integrity or damage in the WM and GM 
regions (Budde et al., 2011). We found a positive correlation between FA values measured in the CC and content of myelin for the studied groups at all-time points (Fig. $6 \mathrm{~b}$ and Table 1 ).

Moreover, we investigated the correlation between clustering coefficients and behavioral variables.

Clustering describes the networks at the local level and depends on their property to form microstructurally similar entities. Indeed, we observed an negative correlation between clustering and the NOR index two weeks after diet onset (Fig. 6c and Table 1).

\begin{tabular}{|c|c|c|c|c|c|c|}
\hline \multicolumn{2}{|c|}{ Correlation parameters (corrected $r^{2}$ ) } & \multicolumn{2}{|c|}{ cupri 2 weeks } & \multicolumn{2}{|c|}{ cupri 4 weeks } & cupri \\
\hline & & $r^{2}$ & $p$ & $r^{2}$ & $p$ & $r^{2}$ \\
\hline FA Thalamus & Distance OF & 0.45 & $<0.01$ & 0.67 & $<0.001$ & 0.61 \\
\hline FA Hippocampus & Time in periphery & 0.58 & $<0.001$ & 0.62 & $<0.001$ & 0.64 \\
\hline FA Cortex & $\begin{array}{l}\text { number of } \mathrm{GFAP}^{+} \text {cell } \\
\text { in Cortex }\end{array}$ & 0.62 & $<0.001$ & 0.63 & $<0.001$ & 0.57 \\
\hline FA Corpus Callosum & PLP myelination & 0.59 & $<0.001$ & 0.64 & $<0.001$ & 0.62 \\
\hline Clustering & NOR index & 0.48 & $<0.01$ & 0.59 & $<0.001$ & 0.62 \\
\hline
\end{tabular}

Table 1 . Table 1 shows $r^{2}$ and $p$ values obtained from correlation analysis for all experimental groups and different parameters

\section{Discussion}

Non-invasive investigation of the brain networks and studies on the relation of cerebral circuits characteristics and microstructural tissue properties is challenging since regional and global pathophysiological processes cannot be robustly delimited through widely available methodological tools. Here, we overcome this gap by linking histopathological analyses of myelin dynamics with diffusion MRI derived metrics of tissue integrity and network characteristics (modularity, clustering) and dissect this essential pathophysiological bridge using the cuprizone model. Moreover, we relate these variables to function and psychopathology studying the behavioral correlates of the de- and remyelination. 
Our results indicate that histological and cytomorphological abnormalities in response to cuprizoneinduced damage are closely interrelated to network properties as measured by diffusion MRI and are directly influenced (to a different extent) by processes occurring in both grey (cortex and thalamus) and white matter (corpus callosum). These structural reorganizations are caused by gradual myelin loss and occurrence of astrocytosis and microgliosis, followed by remyelination processes. Our findings explicitly show how white and grey matter myelination differently affects microstructural integrity and network properties, and how circuits variables parallelize improvement of behavioral performance and psychopathology. While control-like levels of myelin are observed during remyelination, cognitive function does not improve completely throughout remyelination. Hence, cuprizone-treated animals tested with a modified auditory Pavlovian conditioning paradigm were cognitively abnormal upon myelin loss and remained impaired in their performance even after reintroduction of normal food. Interestingly, in the same animals we observed recovery of cognitive performance during remyelination in the memory task. This observation suggests network-specific effects: while hippocampal-memory related functions recover (this study), the auditory thalamocortical network, providing the anatomical basis for the sensory input for fear conditioning with its connection to the limbic system, remains affected (our previous studies and a study by Shin and Liberzon, 2010). Thus, we can hypothesize that persistent cognitive decline depends on alterations occurring at the network level and involves a modified balance of long- to short-range structural similarity dependent tissue reorganization (as shown by modularity alterations in our study). Moreover, the ability of neural circuits to re-wire and recruit higher numbers of neuronal populations or spatially separated neuronal populations, thereby interfering with a proper response to behavioral tasks, could be a potential mechanism underlying disturbed function (Ayache et al., 2015; Buddeberg et al., 2004).

Reorganization of white matter pathways has been described as a potential mechanism to explain these effects (Ayache et al., 2015; Kerschensteiner et al., 2004). This explanation is supported by the results of our correlation analyses between FA values and PLP signal (Table 1), and by reduced excitability at maximal myelin loss probably due to lack of stimulus propagation (Ghaffarian et al., 
2016; Hamada and Kole, 2015). Interestingly, the cuprizone diet leads to a transitory period of hyperexcitability in early phases of remyelination associated with altered activity in the several network regions in vitro (Cerina et al., 2018) and in vivo and affects white and grey matter regions differently (Narayanan et al., 2018). Accordingly, we show that white and grey matter network properties as derived from fractional anisotropy measures clearly decreases during demyelination, with a subsequent increase upon remyelination.

Detrimental effects of myelin loss and inflammation have been shown for the neocortex in animal models of neurodegeneration (Budde et al., 2011; Hübner et al., 2017) and for sensory motor systems of MS patients (Deppe et al., 2013; Fleischer et al., 2016). We could depict reduced FA values in cortex and hippocampus, with a significant negative peak 6 weeks into the diet. Subsequently, FA values of cortex and hippocampus increased with reintroduction of normal food, indicating neural tissue recovery following diet-induced damage and regain of baseline pre-cuprizone behavioral activity. Contrary, thalamus FA values remained very low during early remyelination, indicating that this anatomical structure is more susceptible to demyelination, showing slightly delayed effects compared to the cortex. This may directly influence the thalamo-cortical communications and the network metrics. These mechanisms could be responsible for the lost ability to differentiate auditory stimuli during demyelination and residual deficits with remyelination. Indeed, focal demyelination in the thalamus induces altered sensory responses to stimuli entering the auditory thalamocortical circuitry at a later time point of remyelination compared to the cortex (Narayanan et al., 2018). Similarly, despite the amount of myelin produced by differentiated oligodendrocyte progenitors (Skripuletz et al., 2011; Ziser et al., 2018), inter-hemispheric and interhemispheric connectivity through the $\mathrm{CC}$ is impaired then through cuprizone-induced demyelination and remains abnormal during remyelination. This supports the idea that myelin loss triggers a more permanent and profound decline of neuronal network functionality (Cerina et al., 2018, 2017; Crawford et al., 2009b). The increased clustering observed in MS patients compared to healthy controls represents a costefficient reorganization of the brain with amplified local information flow (Fleischer et al., 2017; Muthuraman et al., 2016; Shu et al., 2016; Tewarie et al., 2014). In addition, increased modularity 
suggests a network reorganization with a modification of the long-range structural similarity and more local homogeneity in response to demyelination (Fleischer et al., 2017; Kocevar et al., 2016;

Muthuraman et al., 2016). We observed an increase of modularity in the demyelination phase and an immediate reversal after stopping the cuprizone diet. These patterns of brain circuitry reorganisation upon de- and remyelination follow a known scheme of brain circuits remodeling during brain development (Chandran et al., 2012; Huang et al., 2013; Cao et al., 2014). Tissue microstructural abnormalities, indicated by FA dynamics in the course of the experiment, could be detected in grey matter regions only. Notably, network topology characteristics obtained from FA values could be detected at the global (whole brain) level, providing us with a more perceptible marker for ongoing structural changes. In contrast, our healthy controls showed lower clustering and lower modularity, demonstrating potentially mirroring aspects of compensation and adaptive reorganization in neighboring anatomical structures during early demyelination and remyelination phases. Several studies have presented evidence that links community structure properties of the brain (e.g., increased modularity) to maintenance of function despite continuous damage, as seen in neurodegenerative disorders (Meunier et al., 2014). These processes of network reorganization are presumably essential to maintain functioning (Kashtan and Alon, 2005; Meunier et al., 2010). It is therefore important to consider that, apart from restored memory skills of mice in the NOR test, anxiety-like behavior in the EPM test and loss of frequency discrimination in the auditory Pavlovian conditioning paradigm were still present upon myelin gain. Similarly, the distance travelled in the OF test was also altered after myelin loss, supporting other recent findings (Bölcskei et al., 2018). The network-based approach applied here bridges ex vivo tracked tissue dynamics and in vivo microanatomy upon myelin loss and renewal, shaping discrete determinants of behavioral adaptive responses.

\section{Conclusion}

Our data provide new links between histopathological myelin properties of the white and grey matter and brain circuits behavior at the network level as derived from MRI driven diffusion imaging. We 
depict the basis for brain circuits modularization under demyelination and behavior abnormalities captured in a spatiotemporal manner. These translational concepts can be applied to address microstructural integrity, brain network responses, functional outcome to track disease courses in CNS autoimmunity or therapeutic responses.

\section{Declarations}

\section{Ethics approval and consent to participate}

Experiments were conducted in accordance with guidelines of local German authorities (LANUV ID: 84-02.04.2015.A585).

\section{Consent for publication}

Not applicable

\section{Availability of data and material}

The parts of the raw datasets are available in the link below due to upload space requirments. The complete dataset used and/or analysed during the current study available from the corresponding author on reasonable request. The data used for creating the figures are available in the given link (https://www.dropbox.com/sh/xmxmzosxrudpx1l/AABM7L_jtkd2z6oi3pnqVNZoa?dl=0).

\section{Competing interests}

All authors report no competing interests.

\section{Funding}

This study was supported by the SFB CRC-128 (B05 to Groppa/Meuth and B06 to Meuth/Budde) and by DFG funding to CF and TB (Fa474/5 and BU1019/15-1).

\section{Authors' contributions}

MC designed and supervised part of the project, performed and analyzed part of the behavioral tests and the ex-vivo experiments. MM designed and performed the whole DTI and connectome analysis. MG performed and analyzed the behavior and the ex-vivo experiments. NK helped with the connectome analysis. AD helped with performing histological evaluations. LW and CF performed the structural MRI and the analysis of myelin content. PH initiated the project and contributed scientifically to it. PS and JGT sorted the MRI data. VF, JK and GGE helped revising the manuscript. VN 
performed and analyzed the pavlovian conditioning paradigm. TB and FZ gave valuable scientific

input to the manuscript. SG and SGM developed, designed and supervised the entire project. MC and MM wrote the manuscript. All authors red and accepted the final version of the manuscript.

\section{Acknowledgements}

We would like to thank Monika Wart, Jana Pravemann and Frank Kurth for the excellent technical assistance. Moreover, we would also like to thank Dr. Jan Strecker for the valuable support for histological evaluation.

\section{References}

Antunes, M., Biala, G., 2012. The novel object recognition memory: neurobiology, test procedure, and its modifications. Cogn. Process. 13, 93-110. https://doi.org/10.1007/s10339-011-0430-z

Ayache, S.S., Créange, A., Farhat, W.H., Zouari, H.G., Lesage, C., Palm, U., Abdellaoui, M., Lefaucheur, J.-P., 2015. Cortical excitability changes over time in progressive multiple sclerosis. Funct. Neurol. 30, 257-63.

Behrens, T.E.J., Berg, H.J., Jbabdi, S., Rushworth, M.F.S., Woolrich, M.W., 2007. Probabilistic diffusion tractography with multiple fibre orientations: What can we gain? Neuroimage 34, 144-155. https://doi.org/10.1016/j.neuroimage.2006.09.018

Bitsch, A., 2000. Acute axonal injury in multiple sclerosis: Correlation with demyelination and inflammation. Brain 123, 1174-1183. https://doi.org/10.1093/brain/123.6.1174

Bölcskei, K., Kriszta, G., Sághy, É., Payrits, M., Sipos, É., Vranesics, A., Berente, Z., Ábrahám, H., Ács, P., Komoly, S., Pintér, E., 2018. Behavioural alterations and morphological changes are attenuated by the lack of TRPA1 receptors in the cuprizone-induced demyelination model in mice. J. Neuroimmunol. 320, 1-10. https://doi.org/10.1016/J.JNEUROIM.2018.03.020

Boretius, S., Escher, A., Dallenga, T., Wrzos, C., Tammer, R., Brück, W., Nessler, S., Frahm, J., Stadelmann, C., 2012. Assessment of lesion pathology in a new animal model of MS by multiparametric MRI and DTI. Neuroimage 59, 2678-88.

https://doi.org/10.1016/j.neuroimage.2011.08.051

Budde, M.D., Janes, L., Gold, E., Turtzo, L.C., Frank, J.A., 2011. The contribution of gliosis to diffusion 
tensor anisotropy and tractography following traumatic brain injury: validation in the rat using Fourier analysis of stained tissue sections. Brain 134, 2248-60. https://doi.org/10.1093/brain/awr161

Buddeberg, B.S., Kerschensteiner, M., Merkler, D., Stadelmann, C., Schwab, M.E., 2004. Behavioral testing strategies in a localized animal model of multiple sclerosis. J. Neuroimmunol. 153, 158-170. https://doi.org/10.1016/j.jneuroim.2004.05.006

Cao, M., Wang, J.-H., Dai, Z.-J., Cao, X.-Y., Jiang, L.-L., Fan, F.-M., Song, X.-W., Xia, M.-R., Shu, N., Dong, Q., Milham, M.P., Castellanos, F.X., Zuo, X.-N., He, Y., 2014. Topological organization of the human brain functional connectome across the lifespan. Dev. Cogn. Neurosci. 7, 76-93. https://doi.org/10.1016/j.dcn.2013.11.004

Cerina, M., Narayanan, V., Delank, A., Meuth, P., Graebenitz, S., Göbel, K., Herrmann, A.M., Albrecht, S., Daldrup, T., Seidenbecher, T., Gorji, A., Kuhlmann, T., Wiendl, H., Kleinschnitz, C., Speckmann, E.J., Pape, H.C., Meuth, S.G., Budde, T., Christian, H., Meuth, S.G., Budde, T., 2018. Protective potential of dimethyl fumarate in a mouse model of thalamocortical demyelination. Brain Struct. Funct. 0, 0. https://doi.org/10.1007/s00429-018-1680-7

Cerina, M., Narayanan, V., Göbel, K., Bittner, S., Ruck, T., Meuth, P., Herrmann, A.M., Stangel, M., Gudi, V., Skripuletz, T., Daldrup, T., Wiendl, H., Seidenbecher, T., Ehling, P., Kleinschnitz, C., Pape, H.C., Budde, T., Meuth, S.G., 2017. The quality of cortical network function recovery depends on localization and degree of axonal demyelination. Brain. Behav. Immun. 59, 103-117. https://doi.org/10.1016/j.bbi.2016.08.014

Chanaday, N.L., Vilcaes, A.A., de Paul, A.L., Torres, A.I., Degano, A.L., Roth, G.A., 2015. Glutamate Release Machinery Is Altered in the Frontal Cortex of Rats with Experimental Autoimmune Encephalomyelitis. Mol. Neurobiol. 51, 1353-1367. https://doi.org/10.1007/s12035-014-8814-6 Chandran P, Upadhyay J, Markosyan S, Lisowski A, Buck W, Chin C-L, Fox G, Luo F, Day M (2012) Magnetic resonance imaging and histological evidence for the blockade of cuprizone-induced demyelination in C57BL/6 mice. Neuroscience 202:446-453.

Chang, E.H., Argyelan, M., Aggarwal, M., Chandon, T.-S.S., Karlsgodt, K.H., Mori, S., Malhotra, A.K., 2017. The role of myelination in measures of white matter integrity: Combination of diffusion tensor 
imaging and two-photon microscopy of CLARITY intact brains. Neuroimage 147, 253-261.

https://doi.org/10.1016/j.neuroimage.2016.11.068

Crawford, D.K., Mangiardi, M., Tiwari-Woodruff, S.K., 2009a. Assaying the functional effects of demyelination and remyelination: Revisiting field potential recordings. J. Neurosci. Methods 182, 25-

33. https://doi.org/10.1016/j.jneumeth.2009.05.013

Crawford, D.K., Mangiardi, M., Xia, X., López-Valdés, H.E., Tiwari-Woodruff, S.K., 2009b. Functional recovery of callosal axons following demyelination: a critical window. Neuroscience 164, 1407-1421. https://doi.org/10.1016/j.neuroscience.2009.09.069

Daldrup, T., Remmes, J., Lesting, J., Gaburro, S., Fendt, M., Meuth, P., Kloke, V., Pape, H.-C., Seidenbecher, T., 2015. Expression of freezing and fear-potentiated startle during sustained fear in mice. Genes. Brain. Behav. https://doi.org/10.1111/gbb.12211

Deppe, M., Krämer, J., Tenberge, J.-G., Marinell, J., Schwindt, W., Deppe, K., Groppa, S., Wiendl, H., Meuth, S.G., 2016. Early silent microstructural degeneration and atrophy of the thalamocortical network in multiple sclerosis. Hum. Brain Mapp. https://doi.org/10.1002/hbm.23144

Deppe, M., Müller, D., Kugel, H., Ruck, T., Wiendl, H., Meuth, S.G., 2013. DTI detects water diffusion abnormalities in the thalamus that correlate with an extremity pain episode in a patient with multiple sclerosis. Neurolmage. Clin. 2, 258-62. https://doi.org/10.1016/j.nicl.2013.01.008

Döring, A., Sloka, S., Lau, L., Mishra, M., van Minnen, J., Zhang, X., Kinniburgh, D., Rivest, S., Yong, V.W., 2015. Stimulation of monocytes, macrophages, and microglia by amphotericin B and macrophage colony-stimulating factor promotes remyelination. J. Neurosci. 35, 1136-48. https://doi.org/10.1523/JNEUROSCI.1797-14.2015

Droby, A., Fleischer, V., Carnini, M., Zimmermann, H., Siffrin, V., Gawehn, J., Erb, M., Hildebrandt, A., Baier, B., Zipp, F., 2015. The impact of isolated lesions on white-matter fiber tracts in multiple sclerosis patients. Neurolmage Clin. 8, 110-116. https://doi.org/10.1016/j.nicl.2015.03.003 Dutta, R., Chang, A., Doud, M.K., Kidd, G.J., Ribaudo, M. V, Young, E.A., Fox, R.J., Staugaitis, S.M., Trapp, B.D., 2011. Demyelination causes synaptic alterations in hippocampi from multiple sclerosis patients. Ann. Neurol. 69, 445-54. https://doi.org/10.1002/ana.22337 
Dutta, R., Chomyk, A.M., Chang, A., Ribaudo, M. V, Deckard, S.A., Doud, M.K., Edberg, D.D., Bai, B., Li, M., Baranzini, S.E., Fox, R.J., Staugaitis, S.M., Macklin, W.B., Trapp, B.D., 2013. Hippocampal demyelination and memory dysfunction are associated with increased levels of the neuronal microRNA miR-124 and reduced AMPA receptors. Ann. Neurol. 73, 637-45.

https://doi.org/10.1002/ana.23860

Ellwardt, E., Pramanik, G., Luchtman, D., Novkovic, T., Jubal, E.R., Vogt, J., Arnoux, I., Vogelaar, C.F., Mandal, S., Schmalz, M., Barger, Z., de Azua, I.R., Kuhlmann, T., Lutz, B., Mittmann, T., Bittner, S., Zipp, F., Stroh, A., 2018. Maladaptive cortical hyperactivity upon recovery from experimental autoimmune encephalomyelitis. Nat. Neurosci. 21, 1392-1403. https://doi.org/10.1038/s41593-0180193-2

Fahimi, H.D., Herzog, V., 1973. a Colorimetric Method for Measurement of the (Peroxidase-Mediated) Oxidation of 3,3'-Diaminobenzidine. J. Histochem. Cytochem. 21, 499-502. https://doi.org/10.1177/21.5.499

Filippi, M., van den Heuvel, M.P., Fornito, A., He, Y., Hulshoff Pol, H.E., Agosta, F., Comi, G., Rocca, M.A., 2013. Assessment of system dysfunction in the brain through MRI-based connectomics. Lancet Neurol. 12, 1189-1199. https://doi.org/10.1016/S1474-4422(13)70144-3

Fleischer, V., Gröger, A., Koirala, N., Droby, A., Muthuraman, M., Kolber, P., Reuter, E., Meuth, S.G., Zipp, F., Groppa, S., 2017. Increased structural white and grey matter network connectivity compensates for functional decline in early multiple sclerosis. Mult. Scler. 23, 432-441.

https://doi.org/10.1177/1352458516651503

Fleischer V, Radetz A, Ciolac D, Muthuraman M, Gonzalez-Escamilla G, Zipp F, Groppa S (2019a) Graph Theoretical Framework of Brain Networks in Multiple Sclerosis: A Review of Concepts. Neuroscience 403:35-53.

Fleischer V, Koirala N, Droby A, Gracien RM, Deichmann R, Ziemann U, Meuth SG, Muthuraman M, Zipp F, Groppa S (2019b) Longitudinal cortical network reorganization in early relapsing-remitting multiple sclerosis. Ther Adv Neurol Disord 12. https://doi.org/10.1016/J.NEUROSCIENCE.2017.10.033 Gamboa, O.L., Tagliazucchi, E., von Wegner, F., Jurcoane, A., Wahl, M., Laufs, H., Ziemann, U., 2014. 
Working memory performance of early MS patients correlates inversely with modularity increases in resting state functional connectivity networks. Neuroimage 94, 385-95.

https://doi.org/10.1016/j.neuroimage.2013.12.008

Ghaffarian, N., Mesgari, M., Cerina, M., Göbel, K., Budde, T., Speckmann, E.-J., Meuth, S.G., Gorji, A., 2016. Thalamocortical-auditory network alterations following cuprizone-induced demyelination. J. Neuroinflammation 13, 160. https://doi.org/10.1186/s12974-016-0629-0

Girvan, M., Newman, M.E.J., 2002. Community structure in social and biological networks. Proc. Natl. Acad. Sci. U. S. A. 99, 7821-6. https://doi.org/10.1073/pnas.122653799

Goulas, A., Uylings, H.B.M., Hilgetag, C.C., 2017. Principles of ipsilateral and contralateral corticocortical connectivity in the mouse. Brain Struct. Funct. 222, 1281-1295.

https://doi.org/10.1007/s00429-016-1277-y

Granberg, T., Fan, Q., Treaba, C.A., Ouellette, R., Herranz, E., Mangeat, G., Louapre, C., Cohen-Adad, J., Klawiter, E.C., Sloane, J.A., Mainero, C., 2017. In vivo characterization of cortical and white matter neuroaxonal pathology in early multiple sclerosis. Brain 140, 2912-2926.

https://doi.org/10.1093/brain/awx247

Gregg, J.R., Herring, N.R., Naydenov, A. V, Hanlin, R.P., Konradi, C., 2009. Downregulation of oligodendrocyte transcripts is associated with impaired prefrontal cortex function in rats. Schizophr. Res. 113, 277-87. https://doi.org/10.1016/j.schres.2009.05.023

Groppa, S., Herzog, J., Falk, D., Riedel, C., Deuschl, G., Volkmann, J., 2014. Physiological and anatomical decomposition of subthalamic neurostimulation effects in essential tremor. Brain 137, 109-121. https://doi.org/10.1093/brain/awt304

Groppa, S., Moeller, F., Siebner, H., Wolff, S., Riedel, C., Deuschl, G., Stephani, U., Siniatchkin, M., 2012. White matter microstructural changes of thalamocortical networks in photosensitivity and idiopathic generalized epilepsy. Epilepsia 53, 668-76. https://doi.org/10.1111/j.1528-

1167.2012.03414.x

Gudi, V., Gingele, S., Skripuletz, T., Stangel, M., 2014. Glial response during cuprizone-induced deand remyelination in the CNS: lessons learned. Front. Cell. Neurosci. 8, 73. 
https://doi.org/10.3389/fncel.2014.00073

Guglielmetti C, Veraart J, Roelant E, Mai Z, Daans J, Van Audekerke J, Naeyaert M, Vanhoutte G, y Palacios RD, Praet J (2016) Diffusion kurtosis imaging probes cortical alterations and white matter pathology following cuprizone induced demyelination and spontaneous remyelination. Neurolmage 125:363-377.

Hall, S.M., 1972. The effect of injections of lysophosphatidyl choline into white matter of the adult mouse spinal cord. J. Cell Sci. 10, 535-46.

Hamada, M.S., Kole, M.H.P., 2015. Myelin loss and axonal ion channel adaptations associated with gray matter neuronal hyperexcitability. J. Neurosci. 35, 7272-86.

https://doi.org/10.1523/JNEUROSCI.4747-14.2015

Hammond, R.S., Tull, L.E., Stackman, R.W., 2004. On the delay-dependent involvement of the hippocampus in object recognition memory. Neurobiol. Learn. Mem. 82, 26-34. https://doi.org/10.1016/j.nlm.2004.03.005

Harsan, L.-A., Dávid, C., Reisert, M., Schnell, S., Hennig, J., von Elverfeldt, D., Staiger, J.F., 2013. Mapping remodeling of thalamocortical projections in the living reeler mouse brain by diffusion tractography. Proc. Natl. Acad. Sci. U. S. A. 110, E1797-806. https://doi.org/10.1073/pnas.1218330110 Huang, H., Shu, N., Mishra, V., Jeon, T., Chalak, L., Wang, Z.J., Rollins, N., Gong, G., Cheng, H., Peng, Y., Dong, Q., He, Y., 2015. Development of human brain structural networks through infancy and childhood. Cereb. Cortex 25, 1389-404. https://doi.org/10.1093/cercor/bht335

Hübner, N.S., Mechling, A.E., Lee, H.-L., Reisert, M., Bienert, T., Hennig, J., von Elverfeldt, D., Harsan, L.-A., 2017. The connectomics of brain demyelination: Functional and structural patterns in the cuprizone mouse model. Neuroimage 146, 1-18. https://doi.org/10.1016/j.neuroimage.2016.11.008 Huntenburg, J.M., Bazin, P.-L., Goulas, A., Tardif, C.L., Villringer, A., Margulies, D.S., 2017. A Systematic Relationship Between Functional Connectivity and Intracortical Myelin in the Human Cerebral Cortex. Cereb. Cortex 27, 981-997. https://doi.org/10.1093/cercor/bhx030 Inano, S., Takao, H., Hayashi, N., Abe, O., Ohtomo, K., 2011. Effects of age and gender on white matter integrity. AJNR. Am. J. Neuroradiol. 32, 2103-9. https://doi.org/10.3174/ajnr.A2785 
Jelescu IO, Zurek M, Winters KV, Veraart J, Rajaratnam A, Kim NS, Babb JS, Shepherd TM, Novikov DS, Kim SG (2016) In vivo quantification of demyelination and recovery using compartment-specific diffusion MRI metrics validated by electron microscopy. Neurolmage 132:104-114.

Kaiser, D., Weise, G., Möller, K., Scheibe, J., Pösel, C., Baasch, S., Gawlitza, M., Lobsien, D., Diederich, K., Minnerup, J., Kranz, A., Boltze, J., Wagner, D.-C., 2014. Spontaneous white matter damage, cognitive decline and neuroinflammation in middle-aged hypertensive rats: an animal model of earlystage cerebral small vessel disease. Acta Neuropathol. Commun. 2, 169.

https://doi.org/10.1186/s40478-014-0169-8

Kashtan, N., Alon, U., 2005. Spontaneous evolution of modularity and network motifs. Proc. Natl.

Acad. Sci. U. S. A. 102, 13773-8. https://doi.org/10.1073/pnas.0503610102

Kerschensteiner, M., Bareyre, F.M., Buddeberg, B.S., Merkler, D., Stadelmann, C., Brück, W., Misgeld, T., Schwab, M.E., 2004. Remodeling of axonal connections contributes to recovery in an animal model of multiple sclerosis. J. Exp. Med. 200, 1027-38. https://doi.org/10.1084/jem.20040452

Kilkenny, C., Browne, W., Cuthill, I.C., Emerson, M., Altman, D.G., 2010. Animal research: reporting in vivo experiments: the ARRIVE guidelines. Br. J. Pharmacol. 160, 1577-9.

https://doi.org/10.1111/j.1476-5381.2010.00872.x

Klaver, R., De Vries, H.E., Schenk, G.J., Geurts, J.J.G., 2013. Grey matter damage in multiple sclerosis: a pathology perspective. Prion 7, 66-75. https://doi.org/10.4161/pri.23499

Kocevar, G., Stamile, C., Hannoun, S., Cotton, F., Vukusic, S., Durand-Dubief, F., Sappey-Marinier, D., 2016. Graph Theory-Based Brain Connectivity for Automatic Classification of Multiple Sclerosis Clinical Courses. Front. Neurosci. 10, 478. https://doi.org/10.3389/fnins.2016.00478

Lein, E.S., Hawrylycz, M.J., Ao, N., Ayres, M., Bensinger, A., Bernard, A., Boe, A.F., Boguski, M.S., Brockway, K.S., Byrnes, E.J., Chen, L., Chen, L., Chen, T.-M., Chi Chin, M., Chong, J., Crook, B.E., Czaplinska, A., Dang, C.N., Datta, S., Dee, N.R., Desaki, A.L., Desta, T., Diep, E., Dolbeare, T.A., Donelan, M.J., Dong, H.-W., Dougherty, J.G., Duncan, B.J., Ebbert, A.J., Eichele, G., Estin, L.K., Faber, C., Facer, B.A., Fields, R., Fischer, S.R., Fliss, T.P., Frensley, C., Gates, S.N., Glattfelder, K.J., Halverson, K.R., Hart, M.R., Hohmann, J.G., Howell, M.P., Jeung, D.P., Johnson, R.A., Karr, P.T., Kawal, R., Kidney, 
J.M., Knapik, R.H., Kuan, C.L., Lake, J.H., Laramee, A.R., Larsen, K.D., Lau, C., Lemon, T.A., Liang, A.J., Liu, Y., Luong, L.T., Michaels, J., Morgan, J.J., Morgan, R.J., Mortrud, M.T., Mosqueda, N.F., Ng, L.L., Ng, R., Orta, G.J., Overly, C.C., Pak, T.H., Parry, S.E., Pathak, S.D., Pearson, O.C., Puchalski, R.B., Riley, Z.L., Rockett, H.R., Rowland, S.A., Royall, J.J., Ruiz, M.J., Sarno, N.R., Schaffnit, K., Shapovalova, N. V., Sivisay, T., Slaughterbeck, C.R., Smith, S.C., Smith, K.A., Smith, B.I., Sodt, A.J., Stewart, N.N., Stumpf, K.-R., Sunkin, S.M., Sutram, M., Tam, A., Teemer, C.D., Thaller, C., Thompson, C.L., Varnam, L.R., Visel, A., Whitlock, R.M., Wohnoutka, P.E., Wolkey, C.K., Wong, V.Y., Wood, M., Yaylaoglu, M.B., Young, R.C., Youngstrom, B.L., Feng Yuan, X., Zhang, B., Zwingman, T.A., Jones, A.R., 2007. Genome-wide atlas of gene expression in the adult mouse brain. Nature 445, 168-176. https://doi.org/10.1038/nature05453 Liang, Z., Li, T., King, J., Zhang, N., 2013. Mapping thalamocortical networks in rat brain using restingstate functional connectivity. Neuroimage 83, 237-44.

https://doi.org/10.1016/j.neuroimage.2013.06.029

Madden, D.J., Bennett, I.J., Burzynska, A., Potter, G.G., Chen, N.-K., Song, A.W., 2012. Diffusion tensor imaging of cerebral white matter integrity in cognitive aging. Biochim. Biophys. Acta 1822, 386-400. https://doi.org/10.1016/j.bbadis.2011.08.003

Mangeat, G., Badji, A., Ouellette, R., Treaba, C.A., Herranz, E., Granberg, T., Louapre, C., Stikov, N., Sloane, J.A., Bellec, P., Mainero, C., Cohen-Adad, J., 2018. Changes in structural network are associated with cortical demyelination in early multiple sclerosis. Hum. Brain Mapp. 39, 2133-2146. https://doi.org/10.1002/hbm.23993

Matsushima, G.K., Morell, P., 2006. The Neurotoxicant, Cuprizone, as a Model to Study Demyelination and Remyelination in the Central Nervous System. Brain Pathol. 11, 107-116.

https://doi.org/10.1111/j.1750-3639.2001.tb00385.x

Meunier, D., Fonlupt, P., Saive, A.-L., Plailly, J., Ravel, N., Royet, J.-P., 2014. Modular structure of functional networks in olfactory memory. Neuroimage 95, 264-275.

https://doi.org/10.1016/J.NEUROIMAGE.2014.03.041

Meunier, D., Lambiotte, R., Bullmore, E.T., 2010. Modular and hierarchically modular organization of brain networks. Front. Neurosci. 4, 200. https://doi.org/10.3389/fnins.2010.00200 
Moeller, F., Muthuraman, M., Stephani, U., Deuschl, G., Raethjen, J., Siniatchkin, M., 2013.

Representation and propagation of epileptic activity in absences and generalized photoparoxysmal responses. Hum. Brain Mapp. 34, 1896-1909. https://doi.org/10.1002/hbm.22026

Muthuraman, M., Fleischer, V., Kolber, P., Luessi, F., Zipp, F., Groppa, S., 2016. Structural Brain Network Characteristics Can Differentiate CIS from Early RRMS. Front. Neurosci. 10, 14. https://doi.org/10.3389/fnins.2016.00014

Nalivaeva, N.N., Turner, A.J., 2013. The amyloid precursor protein: A biochemical enigma in brain development, function and disease. FEBS Lett. 587, 2046-2054.

https://doi.org/10.1016/j.febslet.2013.05.010

Narayanan, V., Cerina, M., Göbel, K., Meuth, P., Herrmann, A.M., Fernandez-Orth, J., Stangel, M., Gudi, V., Skripuletz, T., Daldrup, T., Lesting, J., Schiffler, P., Wiendl, H., Seidenbecher, T., Meuth, S.G., Budde, T., Pape, H.-C., 2018. Impairment of frequency-specific responses associated with altered electrical activity patterns in auditory thalamus following focal and general demyelination. Exp. Neurol. 309, 54-66. https://doi.org/10.1016/j.expneurol.2018.07.010 Narayanan, V., Heiming, R.S., Jansen, F., Lesting, J., Sachser, N., Pape, H.-C., Seidenbecher, T., 2011. Social defeat: impact on fear extinction and amygdala-prefrontal cortical theta synchrony in 5-HTT deficient mice. PLoS One 6, e22600. https://doi.org/10.1371/journal.pone.0022600 Newman, M.E.J., 2006. Modularity and community structure in networks. Proc. Natl. Acad. Sci. U. S. A. 103, 8577-82. https://doi.org/10.1073/pnas.0601602103

Pavuluri, M.N., Yang, S., Kamineni, K., Passarotti, A.M., Srinivasan, G., Harral, E.M., Sweeney, J.A., Zhou, X.J., 2009. Diffusion Tensor Imaging Study of White Matter Fiber Tracts in Pediatric Bipolar Disorder and Attention-Deficit/Hyperactivity Disorder. Biol. Psychiatry 65, 586-593. https://doi.org/10.1016/J.BIOPSYCH.2008.10.015 Potter, L.E., Paylor, J.W., Suh, J.S., Tenorio, G., Caliaperumal, J., Colbourne, F., Baker, G., Winship, I., Kerr, B.J., 2016. Altered excitatory-inhibitory balance within somatosensory cortex is associated with enhanced plasticity and pain sensitivity in a mouse model of multiple sclerosis. J. Neuroinflammation 13, 142. https://doi.org/10.1186/s12974-016-0609-4 
Rubinov, M., Sporns, O., 2010. Complex network measures of brain connectivity: Uses and interpretations. Neuroimage 52, 1059-1069. https://doi.org/10.1016/J.NEUROIMAGE.2009.10.003

Salat, D.H., Tuch, D.S., Greve, D.N., van der Kouwe, A.J.W., Hevelone, N.D., Zaleta, A.K., Rosen, B.R., Fischl, B., Corkin, S., Rosas, H.D., Dale, A.M., 2005. Age-related alterations in white matter microstructure measured by diffusion tensor imaging. Neurobiol. Aging 26, 1215-1227. https://doi.org/10.1016/J.NEUROBIOLAGING.2004.09.017

Schneider, C.A., Rasband, W.S., Eliceiri, K.W., 2012. NIH Image to ImageJ: 25 years of image analysis. Nat. Methods 9, 671-5.

Schultz, V., van der Meer, F., Wrzos, C., Scheidt, U., Bahn, E., Stadelmann, C., Brück, W., Junker, A., 2017. Acutely damaged axons are remyelinated in multiple sclerosis and experimental models of demyelination. Glia 65, 1350-1360. https://doi.org/10.1002/glia.23167

Serra-de-Oliveira, N., Boilesen, S.N., Prado de França Carvalho, C., LeSueur-Maluf, L., Zollner, R. de L., Spadari, R.C., Medalha, C.C., Monteiro de Castro, G., 2015. Behavioural changes observed in demyelination model shares similarities with white matter abnormalities in humans. Behav. Brain Res. 287, 265-275. https://doi.org/10.1016/J.BBR.2015.03.038

Shin, L.M., Liberzon, I., 2010. The neurocircuitry of fear, stress, and anxiety disorders. Neuropsychopharmacology 35, 169-91. https://doi.org/10.1038/npp.2009.83 Shu, N., Duan, Y., Xia, M., Schoonheim, M.M., Huang, J., Ren, Z., Sun, Z., Ye, J., Dong, H., Shi, F.-D., Barkhof, F., Li, K., Liu, Y., 2016. Disrupted topological organization of structural and functional brain connectomes in clinically isolated syndrome and multiple sclerosis. Sci. Rep. 6, 29383.

https://doi.org/10.1038/srep29383

Skripuletz, T., Gudi, V., Hackstette, D., Stangel, M., 2011. De- and remyelination in the CNS white and grey matter induced by cuprizone: the old, the new, and the unexpected. Histol. Histopathol. 26, 1585-97.

Smith, S.M., Jenkinson, M., Woolrich, M.W., Beckmann, C.F., Behrens, T.E.J., Johansen-Berg, H., Bannister, P.R., De Luca, M., Drobnjak, I., Flitney, D.E., Niazy, R.K., Saunders, J., Vickers, J., Zhang, Y., De Stefano, N., Brady, J.M., Matthews, P.M., 2004. Advances in functional and structural MR image 
analysis and implementation as FSL. Neuroimage 23, S208-S219.

https://doi.org/10.1016/j.neuroimage.2004.07.051

Soares, J.M., Marques, P., Alves, V., Sousa, N., 2013. A hitchhiker's guide to diffusion tensor imaging.

Front. Neurosci. 7, 31. https://doi.org/10.3389/fnins.2013.00031

Song, S.-K., Sun, S.-W., Ramsbottom, M.J., Chang, C., Russell, J., Cross, A.H., 2002. Dysmyelination revealed through MRI as increased radial (but unchanged axial) diffusion of water. Neuroimage 17, 1429-36.

Song, S.-K., Yoshino, J., Le, T.Q., Lin, S.-J., Sun, S.-W., Cross, A.H., Armstrong, R.C., 2005. Demyelination increases radial diffusivity in corpus callosum of mouse brain. Neuroimage 26, 132140. https://doi.org/10.1016/j.neuroimage.2005.01.028

Tewarie, P., Hillebrand, A., Schoonheim, M.M., van Dijk, B.W., Geurts, J.J.., Barkhof, F., Polman, C.. ., Stam, C.J., 2014. Functional brain network analysis using minimum spanning trees in Multiple Sclerosis: an MEG source-space study. Neuroimage 88, 308-18.

https://doi.org/10.1016/j.neuroimage.2013.10.022

Tezuka, T., Tamura, M., Kondo, M.A., Sakaue, M., Okada, K., Takemoto, K., Fukunari, A., Miwa, K., Ohzeki, H., Kano, S., Yasumatsu, H., Sawa, A., Kajii, Y., 2013. Cuprizone short-term exposure: astrocytic IL-6 activation and behavioral changes relevant to psychosis. Neurobiol. Dis. 59, 63-8. https://doi.org/10.1016/j.nbd.2013.07.003

Thiessen JD, Zhang Y, Zhang H, Wang L, Buist R, Del Bigio MR, Kong J, Li XM, Martin M (2013) Quantitative MRI and ultrastructural examination of the cuprizone mouse model of demyelination. NMR Biomed 26:1562-1581.

Watts, D.J., Strogatz, S.H., 1998. Collective dynamics of 'small-world' networks. Nature 393, 440-442. https://doi.org/10.1038/30918

Westlye, L.T., Walhovd, K.B., Dale, A.M., Bjornerud, A., Due-Tonnessen, P., Engvig, A., Grydeland, H., Tamnes, C.K., Ostby, Y., Fjell, A.M., 2010. Life-Span Changes of the Human Brain White Matter: Diffusion Tensor Imaging (DTI) and Volumetry. Cereb. Cortex 20, 2055-2068. https://doi.org/10.1093/cercor/bhp280 
Ziser, L., Meyer-Schell, N., Kurniawan, N.D., Sullivan, R., Reutens, D., Chen, M., Vegh, V., 2018. Utility of gradient recalled echo magnetic resonance imaging for the study of myelination in cuprizone mice treated with fingolimod. NMR Biomed. 31, e3877.

\section{Figures}




\begin{tabular}{|c|c|c|c|c|c|c|}
\hline \multicolumn{3}{|c|}{ cuprizone diet } & \multicolumn{4}{|c|}{ remyelination } \\
\hline control & \begin{tabular}{c|} 
\\
2 weeks
\end{tabular} & 4 weeks & 6 weeks & 1 week & \begin{tabular}{c|} 
\\
3 weeks
\end{tabular} & 6 weeks \\
\hline MRI & MRI & MRI & MRI & MRI & MRI & MRI \\
\hline $\begin{array}{c}\text { OF } \\
\text { EPM } \\
\text { NOR } \\
\text { Histo }\end{array}$ & $\begin{array}{c}\text { OF } \\
\text { EPM } \\
\text { NOR } \\
\text { Histo }\end{array}$ & $\begin{array}{c}\text { OF } \\
\text { EPM } \\
\text { NOR } \\
\text { Histo }\end{array}$ & $\begin{array}{c}\text { OF } \\
\text { EPM } \\
\text { NOR } \\
\text { Histo }\end{array}$ & $\begin{array}{c}\text { OF } \\
\text { EPM } \\
\text { NOR } \\
\text { Histo }\end{array}$ & $\begin{array}{c}\text { OF } \\
\text { EPM } \\
\text { NOR } \\
\text { Histo }\end{array}$ & $\begin{array}{c}\text { OF } \\
\text { EPM } \\
\text { NOR } \\
\text { Histo }\end{array}$ \\
\hline $\begin{array}{c}\text { Pavlovian } \\
\text { Conditioning }\end{array}$ & & & $\begin{array}{l}\text { Pavlovian } \\
\text { Conditioning }\end{array}$ & $\begin{array}{c}\text { Pavlovian } \\
\text { Conditioning }\end{array}$ & $\begin{array}{c}\text { Pavlovian } \\
\text { Conditioning }\end{array}$ & \\
\hline
\end{tabular}




\section{Figure 1}

Experimental outline. Schematic representation of the study showing the 7 experimental groups coinciding with different time points before, during and after cuprizone diet. MRI data was performed longitudinally at every time point in the same mouse cohort (continuous blue line). New cohorts of mice were used at each time points to assess locomotor-, anxiety-like behavior and memory abilities. All mice underwent the same tests and some of them were used for histological evaluation at every time point. Additional cohorts were used to assess effects of pavlovian conditioning paradigm only at the indicated time points. 

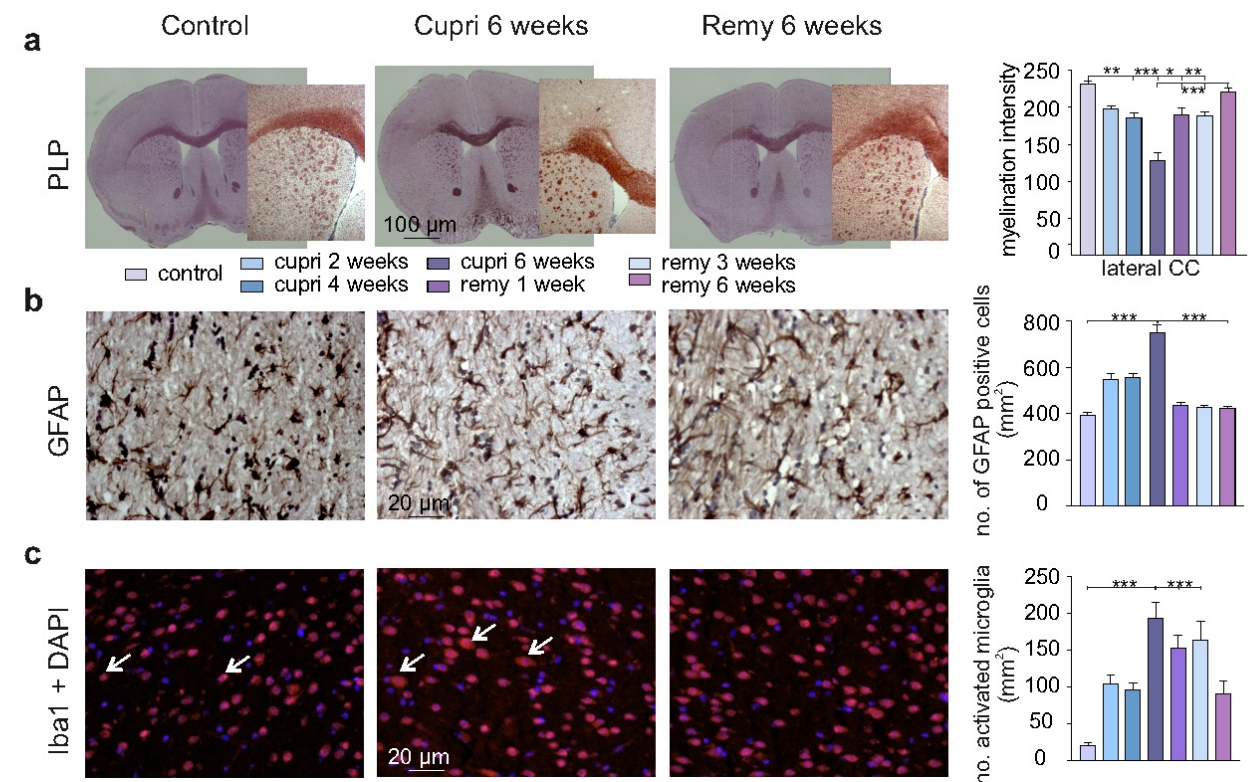

d
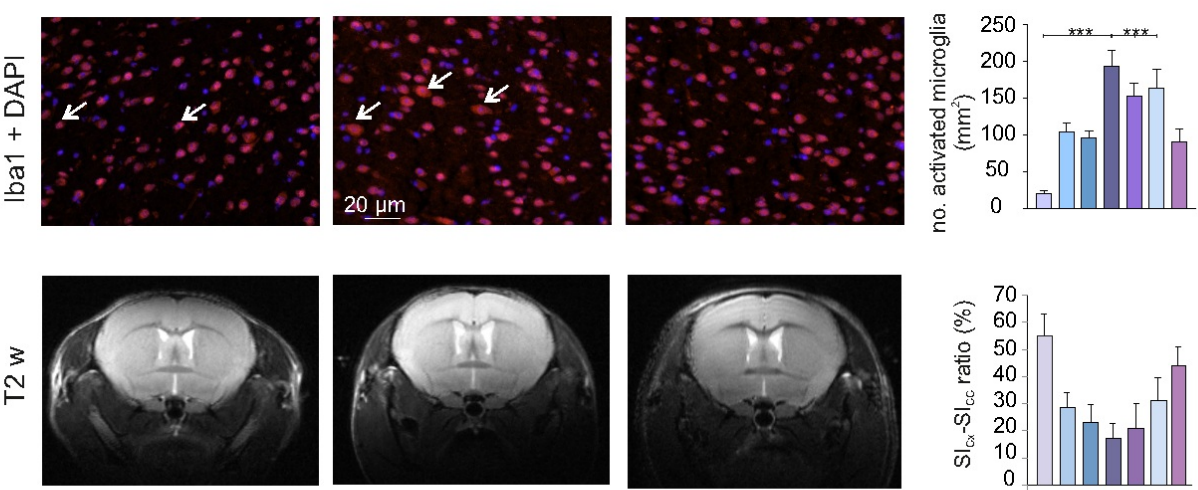

Figure 2

Figure 2 
Structural and anatomical white matter changes during de- and remyelination in the cuprizone model. Example immunohistochemical images of coronal mouse slices containing the corpus callosum (CC) in control conditions (1st column), at 6 weeks after starting the cuprizone diet (cupri 6 weeks - full demyelination, 2nd column), and at full remyelination 6 weeks after reintroduction of normal food (3rd column). On the right of each panel, bar graphs show quantifications of changes. Stained for: (a) myelin specific marker PLP; (b) astrocytic specific marker GFAP; (c) specific microglial cell marker lba1. Activated cells are indicated by white arrows; (d) exemplary T2 weighted images obtained in living mice during a longitudinal MRI scan. Pictures show frontal part of mouse brain containing neocortex and CC from control, cupri 6 weeks and remy 6 weeks mice. Bar graph shows the ratio calculated between the intensity of the myelin signal observed in Cx (SCx) and CC (SCC). ${ }^{*} \mathrm{p}$ $<0.05 ; * * p<0.01 ; * * * p<0.001$. 
a

$\stackrel{a}{a}$

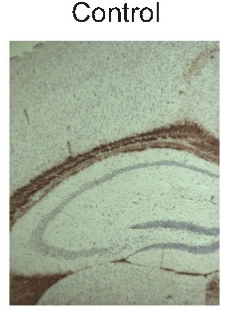

b

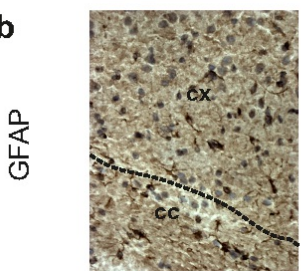

c
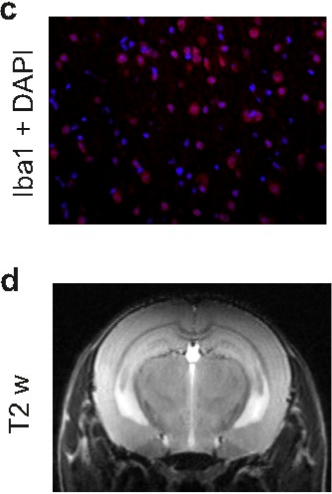

Cupri 6 weeks
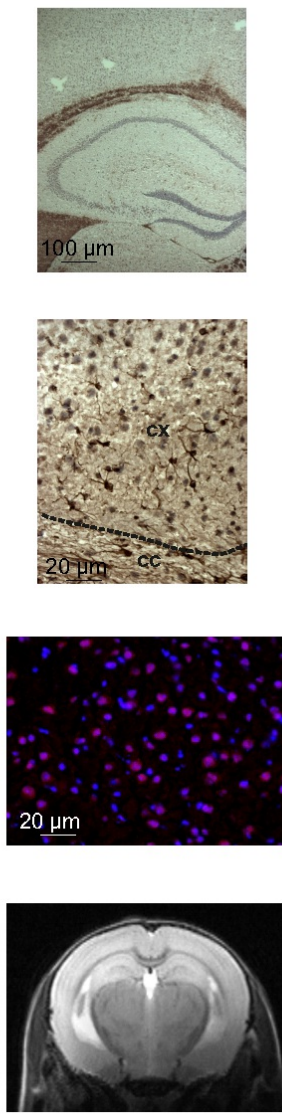

Remy 6 weeks
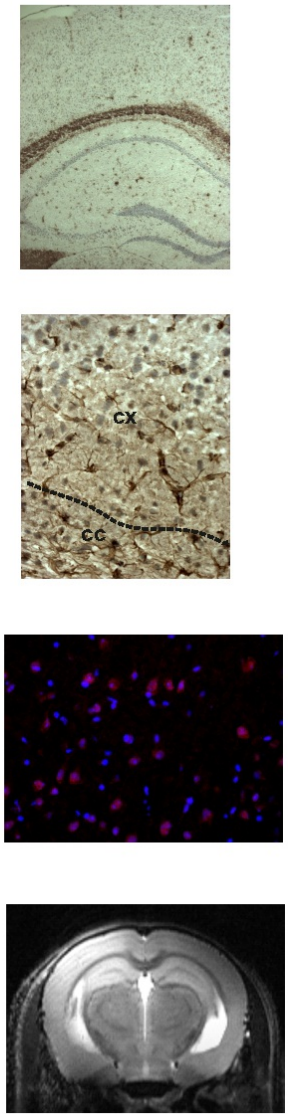
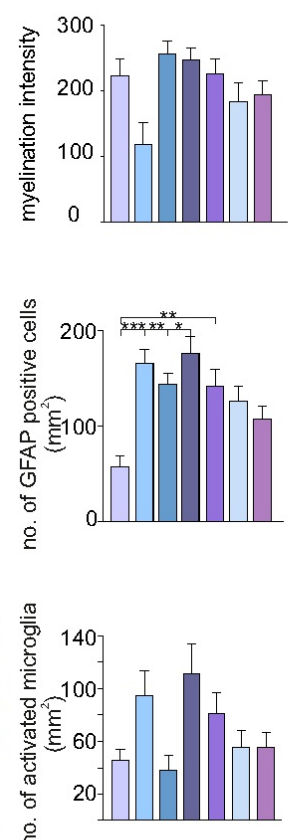

$\square$ control

$\square$ cupri 2 weeks

$\square$ cupri 4 weeks

$\square$ cupri 6 weeks

$\square$ remy 1 week

$\square$ remy 6 weeks

Figure 3

Figure 3 
Structural and anatomical grey matter changes during de- and remyelination in the cuprizone model. Example immunohistochemical images of coronal mouse slices containing the neocortex (Cx) in control conditions (1st column), at 6 weeks after starting the cuprizone diet (cupri 6 weeks - full demyelination, 2nd column), and at full remyelination 6 weeks after reintroduction of normal food (3rd column). On the right of each panel, bar graphs show quantifications of changes. Stained for: (a) myelin specific marker PLP; (b) astrocytic specific marker GFAP; (c) specific microglial cell marker Iba1. Activated cells are indicated by white arrows; (d) exemplary T2 weighted images obtained in living mice during a longitudinal MRI scan. Pictures show frontal part of mouse brain containing neocortex, hippocampus and CC. $* p<0.05 ; * * p<0.01 ; * * * p<0.001$. 

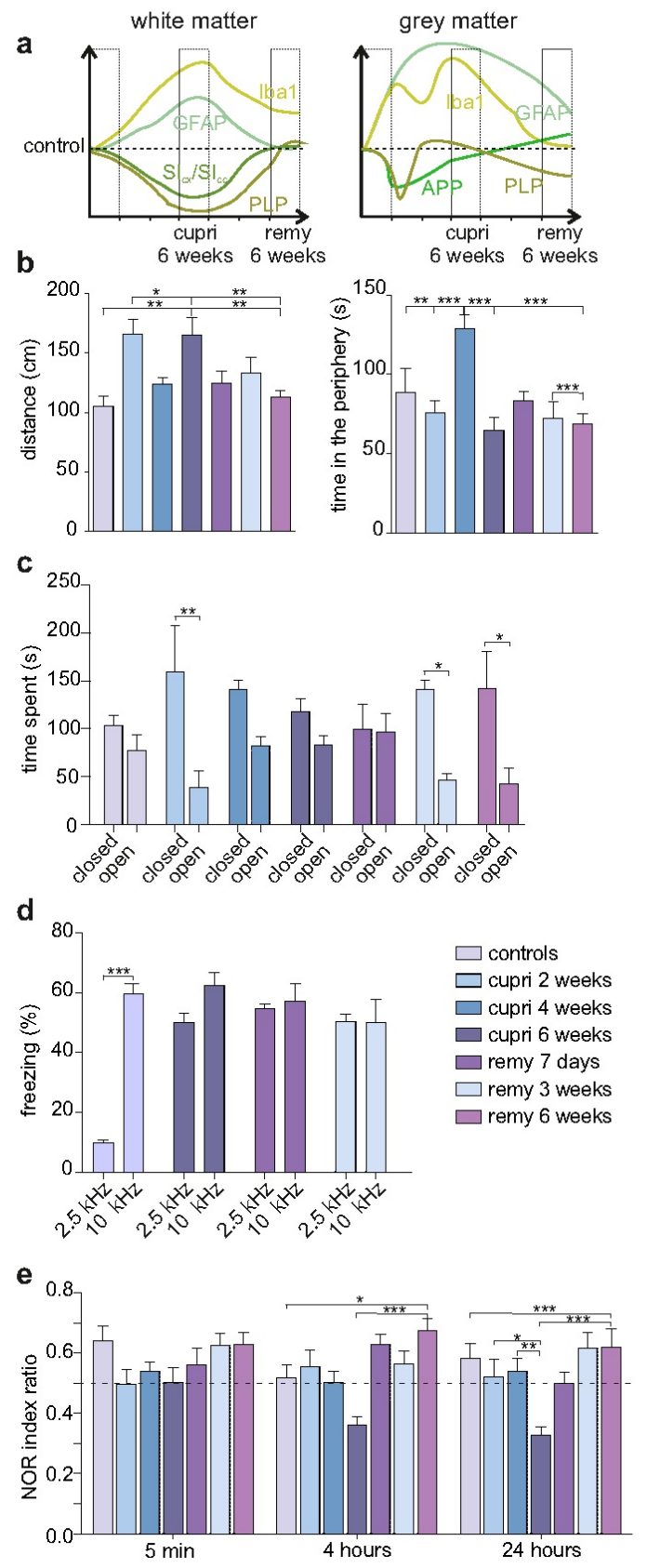

Figure 4

Figure 4 
Behavioral correlates of general de- and remyelination in the cuprizone model. (a) schematic representation of the time course of histopathological markers for structural impairment in the cuprizone model; (b) bar graphs showing travelled distance and time spent in the periphery in the Open Field test; (c) bar graphs show the results of the EPM test; (d) bar graphs show the results of the auditory Pavlovian conditioning paradigm conducted using $2.5 \mathrm{kHz}$ or $10 \mathrm{kHz}$, where the latter is the conditioning stimulus associated to the foot shock; (e) bar graphs show NOR index calculated 15 min, 4 hours and 24 hours.

$$
* p<0.05 ; * * p<0.01 ; * * * p<0.001 \text {. }
$$


a

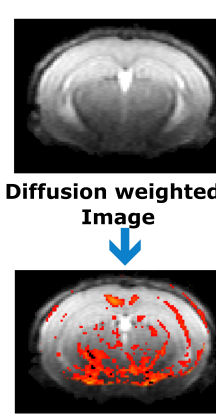

Fractional Anisotropy $\downarrow$

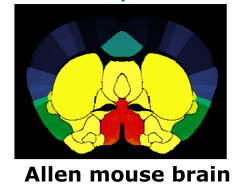

Allen mouse brain atlas mask

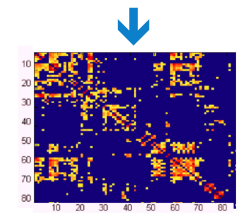

Connectivity matrix

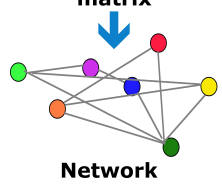

measures b

FA regional values
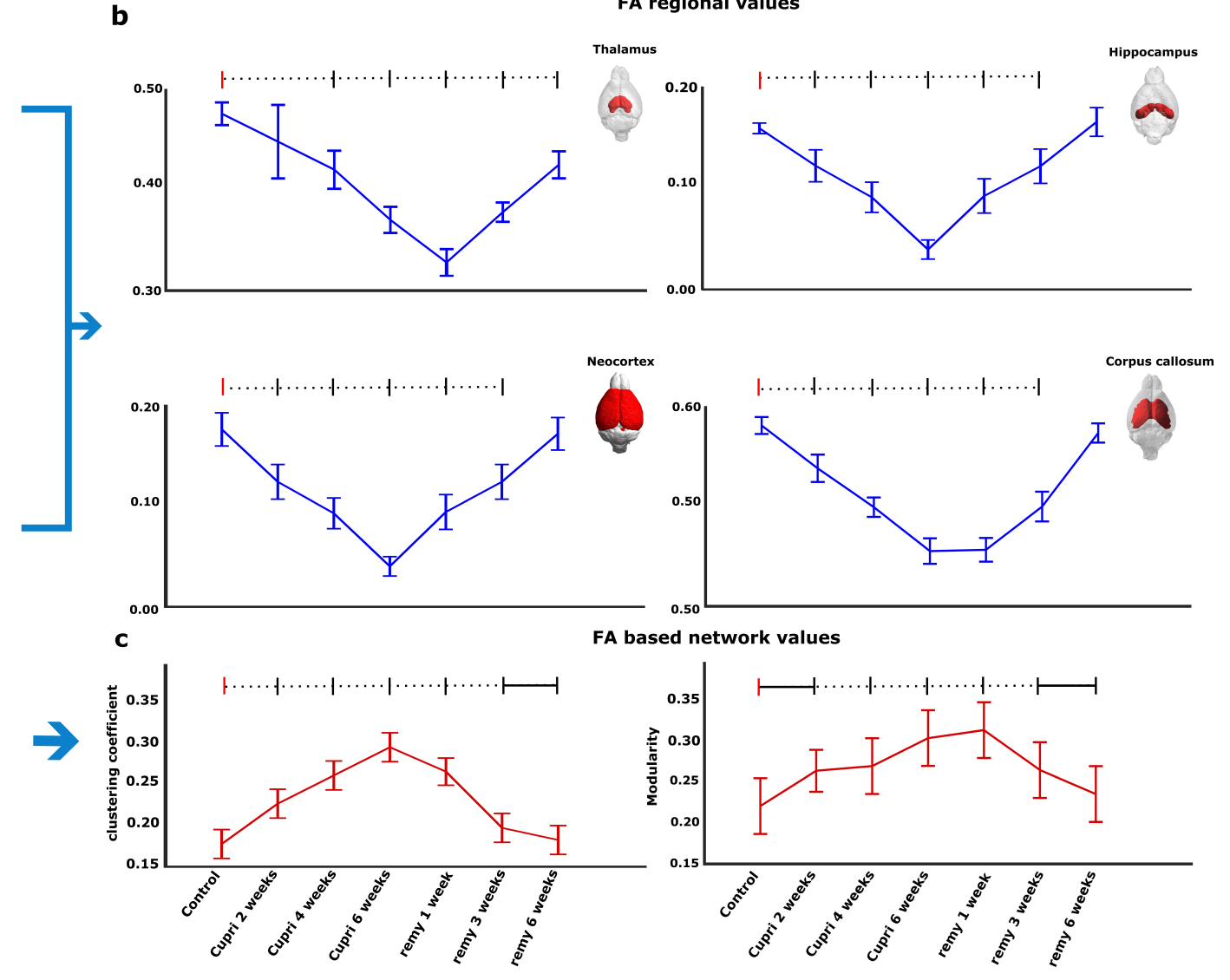

Figure 5

Structural dynamics of de- and remyelination. (a) schematic representation of the methodological approach used to perform neuronal network analyses. Diffusion tensor images were used to calculate the fractional anisotropy (FA), and a connectivity matrix was built with the help of an anatomical mask. (b) regional FA values in the thalamus (left upper panel), in the neocortex (left lower panel) and the hippocampus (right upper panel at all and CC (right lower panel) investigated at all-time points. (c) FA-based network values had increased clustering coefficients and modularity compared to control. Horizontal black lines represent significance of a given time point in comparison to control: $p<0.01$. Dashed lines represent significance of a given time point in comparison to control: $p<0.001$. 
a.

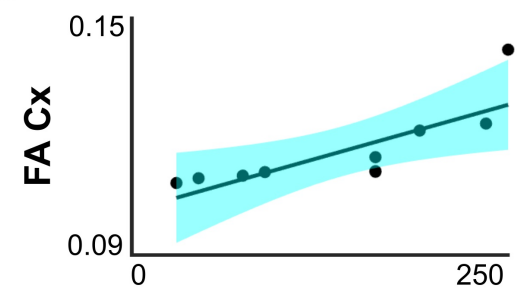

b.

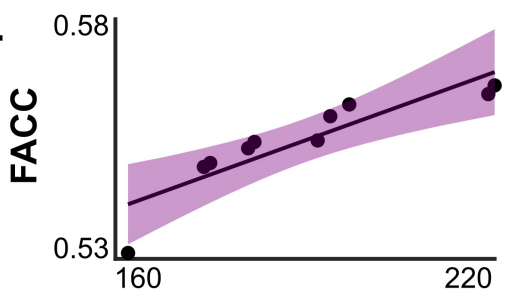

c.

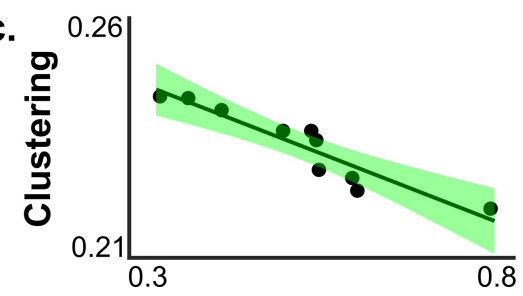

no. GFAP+ cells in Cx
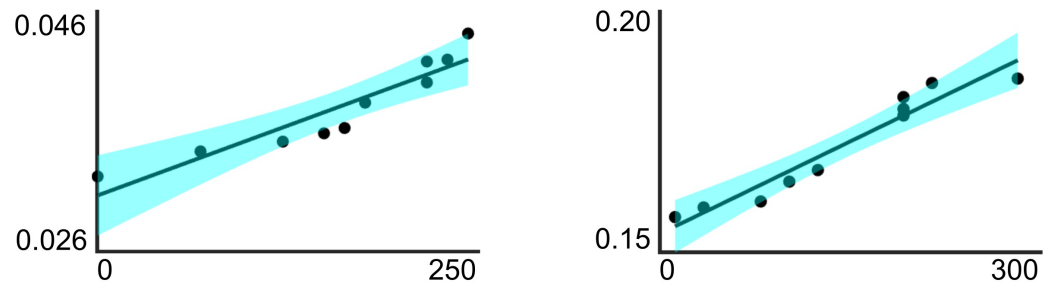

PLP signal (Myelination levels)
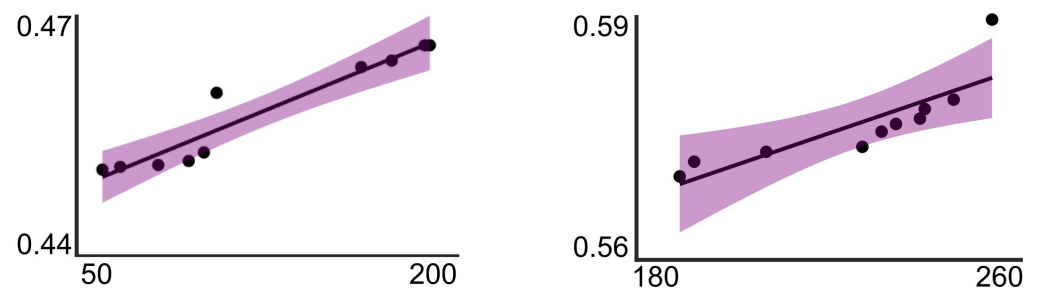

NOR index
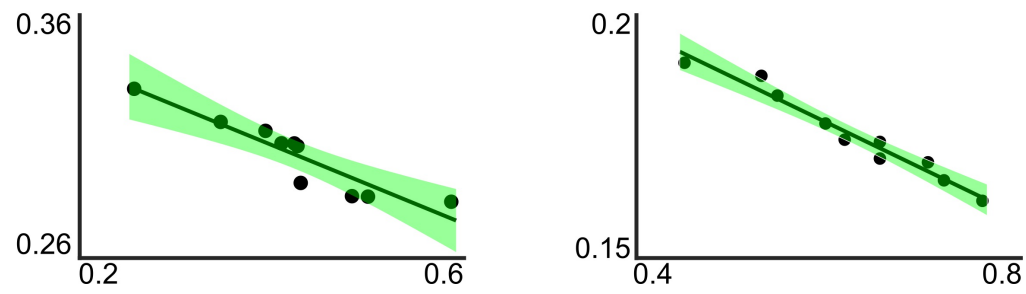

Figure 6

Correlation analyses. (a) correlation plots between FA values in the cortex and number of GFAP positive cells found in the cortex. Three time points corresponding to onset of demyelination (cupri 2 weeks, left column), full demyelination (cupri 6 weeks, middle column) and full remyelination (remy 6 weeks, right column). (b) correlation plots between FA values in the corpus callosum and PLP signal intensity (indication for myelination) in the corpus callosum. Three time points corresponding to the start of demyelination (cupri 2 weeks, left column), full demyelination (cupri 6 weeks, middle column) and full remyelination (remy 6 weeks, right column). (c) correlation plots between clustering (indicator of network activity) and the NOR index. Three time points corresponding to the start of demyelination (cupri 2 weeks, left column), full demyelination (cupri 6 weeks, middle column) and full remyelination (remy 6 weeks, right column). $r 2$ and $p$ values are given in Table 1. 
This is a list of supplementary files associated with this preprint. Click to download.

Suppl. Fig. 5.pdf

Suppl. Fig. 4.pdf

Suppl. Fig. 2.pdf

SUPPLEMENTS_ON.docx

Suppl. Fig. 1.pdf

Suppl. Fig. 3.pdf 